\title{
Some Uncomfortable Arithmetic Regarding Europe's Public Finances
}

Delia Velculescu 


\title{
IMF Working Paper
}

European Department

\section{Some Uncomfortable Arithmetic Regarding Europe's Public Finances Prepared by Delia Velculescu ${ }^{1}$}

Authorized for distribution by James Morsink

July 2010

\begin{abstract}
This Working Paper should not be reported as representing the views of the IMF.

The views expressed in this Working Paper are those of the author(s) and do not necessarily represent those of the IMF or IMF policy. Working Papers describe research in progress by the author(s) and are published to elicit comments and to further debate.
\end{abstract}

Traditional fiscal indicators focused on measures of current deficits and debt miss the potentially important implications of current policies for future public finances. This could be problematic, including in the case of Europe, where population aging is expected to pose additional fiscal costs not captured by such indicators. To better gauge the state of public finances in the EU27 countries, this paper derives forward-looking fiscal measures of intertemporal net worth both directly from the European Commission's Aging Working Group's long-run indicators and using a comprehensive public-sector balance sheet approach. These measures could be used as an "early warning" mechanism and also as a communication device with the public. Current estimates indicate that, on existing policies, the intertemporal net worth of the EU27 is deeply negative, even in excess of its GDP level, and is projected to worsen further over time. This suggests that Europe's current policies need to be significantly strengthened to bring future liabilities in line with the EU governments' capacity to generate assets.

JEL Classification Numbers: $\quad$ E62, H68, H87, J10

Keywords: $\quad$ Fiscal Policy, Fiscal Sustainability, Aging, Public Sector Balance Sheet Author's E-Mail Address: dvelculescu@imf.org

\footnotetext{
${ }^{1}$ The author wishes to thank especially Bob Traa for developing the comprehensive public sector balance sheet methodology used in this paper in order to make the challenge of population aging more intuitive to the broader public and for his valuable support and suggestions, James Morsink, Mark Allen, Albert Jaeger, and all participants in the IMF's European Department Seminar for useful comments, and David Velasquez for outstanding research assistance.
} 
I. Introduction..... 3

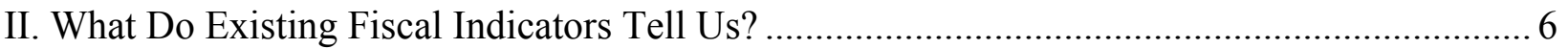

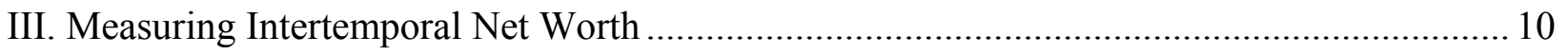

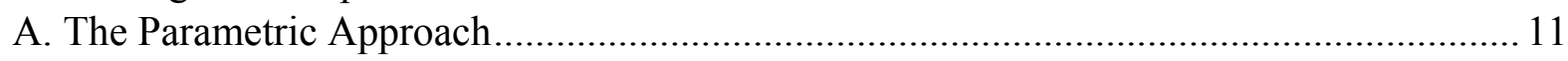

B. The Comprehensive Balance-Sheet Approach ........................................................... 14

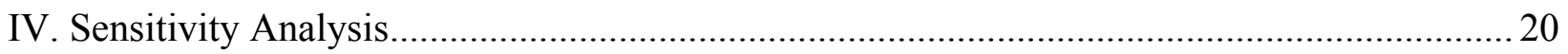

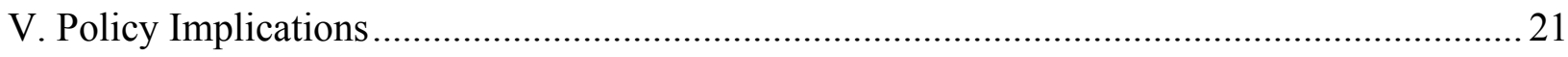

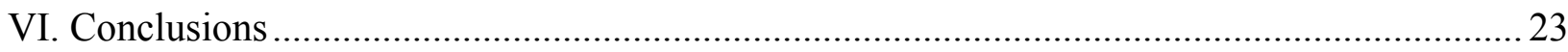

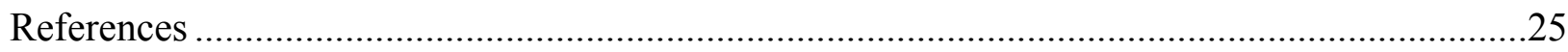

Mathematical Appendix: Comprehensive Net Worth and the S1 and S2 Sustainability

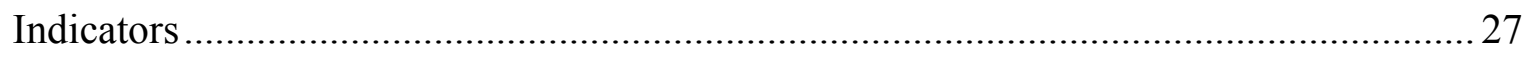

Tables

1. EU27: Traditional Balance Sheet, 2005-09 ......................................................... 14

2. $\quad$ EU27 : Public Sector Comprehensive Balance Sheet, 2009-15 ................................... 18

3. $\quad$ EU27 : Sensitivity Analysis, Intertemporal Net Worth.............................................. 21

4. Intertemporal Net Worth (Balance Sheet Approach), and Required Upfront

Adjustment to Bring Net Worth Into Balance or the Deficit to

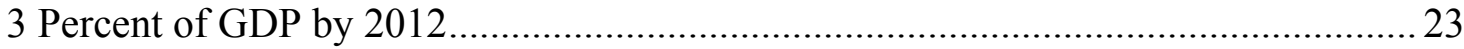

Figures

1. Traditional Fiscal Indicators, 2009 …..................................................................... 7

2. EU27: Population Projections ................................................................................. 8

3. European Commission Long-Term Indicators ................................................. 9

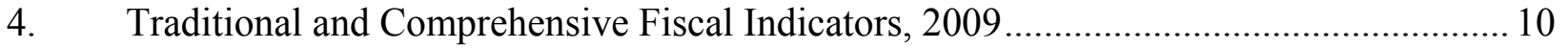

5. Intertemporal Net Worth Derived from S1 and S2 ........................................... 11

6. Updated Intertemporal Net Worth Derived from S1 and S2 ...................................... 12

7. EU27: Long-Run Macroeconomic Projections .......................................................... 16

8. EU27: Long-Run Fiscal Projections ..................................................................... 17

9. Intertemporal Net Worth Derived from the Balance Sheet Approach ........................... 19

10. Long-Term Gains from a One Percent Upfront Permanent Fiscal Adjustment ............... 22

Box 1. Estimating Intertemporal Net Worth From the EC's S1 and S2 Indicators-

A Shortcut 


\section{INTRODUCTION}

The 2009-10 crisis in Europe has unmasked the vulnerability of its public finances. Following the 2009 global downturn, which led to deteriorating public finances and weak growth in many European countries, in April-May 2010, markets began to question the ability of some euro-zone members to make good on their debt payments to creditors. This resulted in temporary panic, with spiking spreads on government bonds. What this episode reflected was a manifestation of the unyielding force of what economists call "the intertemporal budget constraint," which requires governments to be able to generate enough fiscal surpluses in the future (in excess of their interest payment needs) to meet their current (net) debt obligations. Often thought of as a mere theoretical concept that only applies in the long run, this constraint can become binding much sooner, if fiscal imbalances, coupled with a weak outlook, become so large that they are no longer thought of as sustainable, thus telescoping problems seemingly operating on a long-term horizon back into the present. In the recent European case, this led to an EU-IMF support package for one of the eurozone members and a large EU-ECB-IMF stabilization package for the euro zone.

Traditional fiscal indicators do not always correctly capture the "true" state of public finances. Such indicators - including different measures of deficits (overall, primary, structural), gross debt, and even public sector financial net worth - are generally used to quantify the effects of past and current policies and events on countries' current fiscal positions. But, being backwardlooking by definition, these deficit and debt indicators miss the implications of current policies for future public finances. Such implications can be significant, including when population aging is expected to pose additional large fiscal costs, as is the case in many countries, including in Europe. Consequently, traditional indicators offer only a partial picture of public finances and do not take into account information that can be important and is already available. ${ }^{2}$ Moreover, by lacking a forward-looking component, they are also not directly linked to the above-mentioned intertemporal budget constraint, which, when binding, can have large economic repercussions.

\section{Despite their shortcomings, traditional indicators still largely constitute the basis for policy- making decisions under existing national and international frameworks. For example, many countries have national policies in place which target the level of the deficit, structural deficit, expenditures, or debt. Moreover, Europe's Stability and Growth Pact (SGP) requires that members' overall deficits be maintained below 3 percent of GDP and gross debt be kept below 60 percent of GDP. ${ }^{3}$ These limits were agreed at the introduction of the euro based on both political and economic theory considerations and for simple operational reasons, given that they can be relatively easily measured and explained to the general public.}

\section{The emphasis on traditional indicators can lead to suboptimal or counterproductive policies, especially at times of crisis. Under the existing framework, countries whose deficits have}

\footnotetext{
${ }^{2}$ Population aging, unlike other macroeconomic shocks (such as natural disasters, wars, financial crisis, etc.) is somewhat easier to predict, to the extent that known past and current fertility and mortality rates can be used to project the future age-composition of populations, and given that such rates change only slowly over time. However, immigration trends may be more difficult to project, as they are influenced by other macroeconomic shocks.

${ }^{3}$ The so-called Medium Term Objectives (MTO) under the SGP target structural balances over the medium term. These indicators are intended to be more forward-looking and tailored to individual country circumstances, though they only capture a small part of long-run aging costs.
} 
deteriorated significantly are required (under the Excessive Deficit Procedure, or EDP) to undertake a relatively larger fiscal effort to return to the prescribed Maastricht limit as compared to peers that have lower deficits - which are seen as having more "fiscal space." While these inferences appear correct, they do not fully take account of the relative long-run fiscal positions of countries, which can make such inferences incomplete or even misleading. Moreover, it has been documented that, in downturns, countries resort more frequently to short-run temporary solutions to lower their deficits, which may not improve and could even worsen their long-run fiscal positions. ${ }^{4}$ One example is the recent trend seen in some Emerging European countries that are now partially back-tracking on their pension reforms by lowering or suspending the fiscal contributions to their private pension systems in order to reduce their short-run deficits and debt. ${ }^{5}$ These actions are the result of a perception of being effectively "punished" in an international context for having undertaken pension reforms, because such reforms temporarily increase deficits and debt - in principle working against the SGP criteria that apply uniformly to both reformers and non-reformers. These tensions now surfacing within national policies in a number of countries could have potentially negative long-run consequences for these economies.

Hence, an increasing awareness is slowly emerging regarding the need to integrate more fully the essential long-run considerations into policy-making, including through new analytical tools. The European Commission's Aging-Working Group has developed and published two sustainability indicators that take into account both current fiscal positions and aging costs. ${ }^{6}$ The academic literature has also produced similar analyses, including, more recently, Gokhale's (2009) measures of fiscal imbalance for the EU and the US, Auerbach's (2007) fiscal gap for the US, and Cecchetti et al.'s (2010) debt projections for industrial countries. ${ }^{7}$ Still, these measures have remained indicative, are relatively little known by the general public, and do not carry the same political weight as traditional indicators, perhaps because of their complexity and the difficulty of explaining them to voters. Interestingly, in light of the 2010 fiscal crisis in Europe, forward-looking analyses are now increasingly getting traction with market participants (Ghezzi and Keller, 2010).

The present paper proposes alternative forward-looking indicators that measure the public sector's net worth for $\mathbf{E U}$ countries in an intertemporal perspective. These can be calculated directly from the EC's forward indicators, or can be derived using the public-sector comprehensive balance-sheet framework developed by Traa (2006). ${ }^{8}$ Measures of the public sector's intertemporal net worth are one logical next step beyond what governments are already doing, building on the financial net worth concept but adding a forward-looking element. The idea is that they can shed additional light on the state of Europe's public finances and can be used in the public debate to communicate policy needs to the general public.

\footnotetext{
${ }^{4}$ See Milesi-Ferretti (2003) and von Hagen, and Wolff (2006) on theoretical and empirical analyses of temporary solutions, including creative accounting, for the European Union.

${ }^{5}$ Estonia, Lithuania, Latvia, Slovakia, and Romania have already undertaken measures to this effect. Croatia and Poland have been contemplating similar measures (see http://www.aegonglobalpensions.com/base/Templates/Standard.aspx $? \mathrm{id}=417 \&$ epslanguage=en\&npid=11665\&srcid=415).

${ }^{6}$ See the European Commission's 2009 Sustainability Report.

${ }^{7}$ For a discussion of general considerations see Auerbach (2008). An early literature on this topic developed in the 1990s. See, for example, Chand and Jaeger (1996), Disney (2001), and references therein.
}

${ }^{8}$ See, for example, Velculescu (2010), Traa (2009), and Traa (2006) for more recent applications of the comprehensive balance sheet approach to Poland, Greece, and Germany. 
What is the public-sector's intertemporal net worth? It can be thought of as the mirror image of the EC's Aging-Working Group sustainability indicators. Rather than quantifying the upfront primary balance effort required to satisfy a given intertemporal budget constraint (which is a flow measure), it reflects the total current and projected future net liabilities of the public sector under unchanged policies (which is a stock measure). ${ }^{9}$ It thus complements the traditional current net worth position of a government, which is backward looking, with a forward-looking component that takes into account the effects of current fiscal policies on future assets and liabilities, to see if the intertemporal budget constraint is satisfied or not. ${ }^{10}$ In this sense, it functions as a "thermometer" measuring the health (i.e. sustainability) of public finances at each point in time. "Good" policies will lower the "temperature" by strengthening the public sector's balance sheet, while "bad" policies would deepen the shortfall, raising the "temperature."

It can provide early warning signs of fiscal unsustainability. For example, in the context of population aging, traditional indicators often fail to signal a problem. However, the public sector's intertemporal net worth could be negative if aging causes large increases in future public expenditures (included in the balance sheet in NPV terms), if current policies are not calibrated to generate enough resources to meet these obligations projected for the future in addition to the already existing ones. In this case, actions would need to be taken to strengthen policies and bring total assets at least in line with total intertemporal liabilities, or market forces will eventually emerge to reduce liabilities in line with existing and prospective assets. Since fiscal adjustment is often difficult and requires time for consultation with the public, there is great value in having information on prospective fiscal inconsistency well in advance - that is why the intertemporal net worth can act as an early warning system.

\section{It can also help to communicate policy needs in an intuitive way that could be somewhat easier to grasp by the general public. The literature offers a variety of sophisticated frameworks, such as overlapping-generation models and computable dynamic general-equilibrium models to analyze the long-run effects of fiscal policies. However, these tend to have only a limited impact beyond academic circles, perhaps because of their complexity. Even the EC's Aging-Working Group indicators and similar "primary fiscal gap" measures developed by others reach a relatively limited audience partly due to the difficulty of relaying their message to the median voter. The intertemporal net worth indicators developed here complement the already existing measures. They may also be somewhat easier to use as a communication device with the public, to the extent that people may have a better intuitive understanding of wealth and concepts of net worth as the difference of assets and liabilities, expressed in a given currency or as a percentage of income.}

\footnotetext{
${ }^{9}$ The projected future net liabilities under unchanged policies include pensions not only of individuals already in the system, but also of all future generations that have not yet been born. Hence, they do not represent only contracted obligations, but also prospective pension debt. Moreover, the projected future pension payments (and corresponding contributions to the system) are assumed to be governed by the current pension legislation. It is in this sense that they capture the effects of "current policies."

${ }^{10}$ The intertemporal net worth measures derived here represent, therefore, only counterfactual quantifications of the gap that would arise if current policies were not changed, relative to the intertemporal budget constraint. Clearly, if a gap exists, then policies will eventually have to change to ensure that the budget constraint is satisfied. Indeed, in general equilibrium models, such policy changes are required to ensure that the model is internally consistent. This paper does not attempt to model such policy changes, but rather to identify if they will be needed on not.
} 
The paper is organized as follows. Section II describes in more detail the existing fiscal indicators and their limitations. Section III outlines how the measures of intertemporal net worth are constructed and presents some results for the EU27. Section IV draws some policy implications in a cross country context, and section $\mathrm{V}$ concludes with a summary of the findings.

\section{What Do EXISTING FisCAL Indicators TELL Us?}

Traditional indicators point to a deterioration in Europe's current fiscal position. The 2008-09 global downturn led to a fall in fiscal revenues in all European Union (EU27) countries, reflecting the automatically stabilizing response of the fiscal accounts to the cycle. Moreover, depending on their fiscal and macroeconomic starting position, different governments responded to the crisis in a variety of ways: some trying looser fiscal policies to support growth, others tightening fiscal policy to limit damage to sustainability. Consequently, the EU27 headline deficit increased from around 2 to close to 7 percent of GDP from 2008 to 2009, with some countries' deficits rising above 10 percent of GDP. During the same period, the union's debt-to-GDP ratio rose by about 12 percentage points to about 74 percent of GDP. While a few countries tightened policies, or at least put in place structures to recover from the fiscal deterioration in the recession, the EU as a whole loosened its fiscal stance substantially, as reflected in a worsening of its permanent structural balance by close to 2 percent of GDP (Figure 1).

But the specter of population aging is expected to weigh heavily on future public finances. Looking beyond the current difficult times, all EU countries expect a significant aging of their populations. Working populations are falling in most of the EU countries, and the union's old-age dependency ratio is expected to more than double from 25 to over 50 percent between 2008 and 2060 , with some countries' ratios getting close to 70 percent (Figure 2). These projections essentially imply that in 2060, for each pensioner there will be, on average, only two workers, or less in some cases, rather than four, as is currently the case. This is expected to put progressive pressure on public finances, especially for those countries whose demographics are deteriorating relatively more, but which have made little progress on pension reforms so far and thus still rely on paying pensions from taxes on the existing (but diminishing) workforce.

Forward-looking indicators suggest that fiscal sustainability is even more seriously imperiled than current fiscal positions suggest. While traditional indicators only focus on countries' current fiscal positions and backward-looking debt, more comprehensive indicators of fiscal sustainability can also capture the effects of population aging on future fiscal outcomes, thus potentially providing a more accurate description of the state of public finances and their sustainability at any given point in time. The indicators developed by the EC's Aging-Working Group are one example of such measures. The S1 indicator aims to quantify the required upfront fiscal adjustment needed to reach the Maastricht debt-to-GDP ratio of 60 percent in 2060. The S2 indicator estimates the adjustment required to satisfy the government's intertemporal budget constraint over an infinite horizon. According to these measures, the EU's fiscal position is unsustainable, requiring a large upfront permanent fiscal adjustment of some 6 percent of GDP to bring public debt to the Maastricht limit or into intertemporal balance (Figure 3). 
Figure 1. Traditional Fiscal Indicators, 2009

(In percent of GDP)

Debt levels have deteriorated, and financial net worth is negative for most countries.
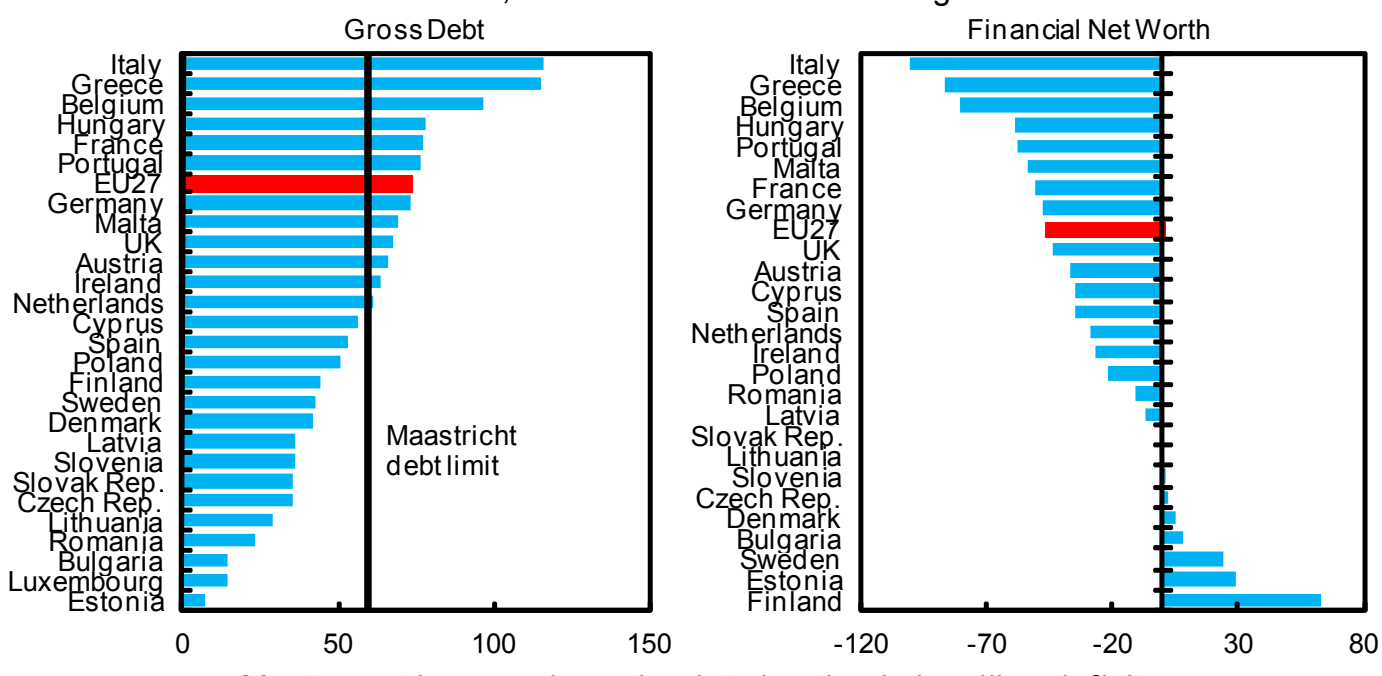

Most countries experienced a deterioration in headline deficits.
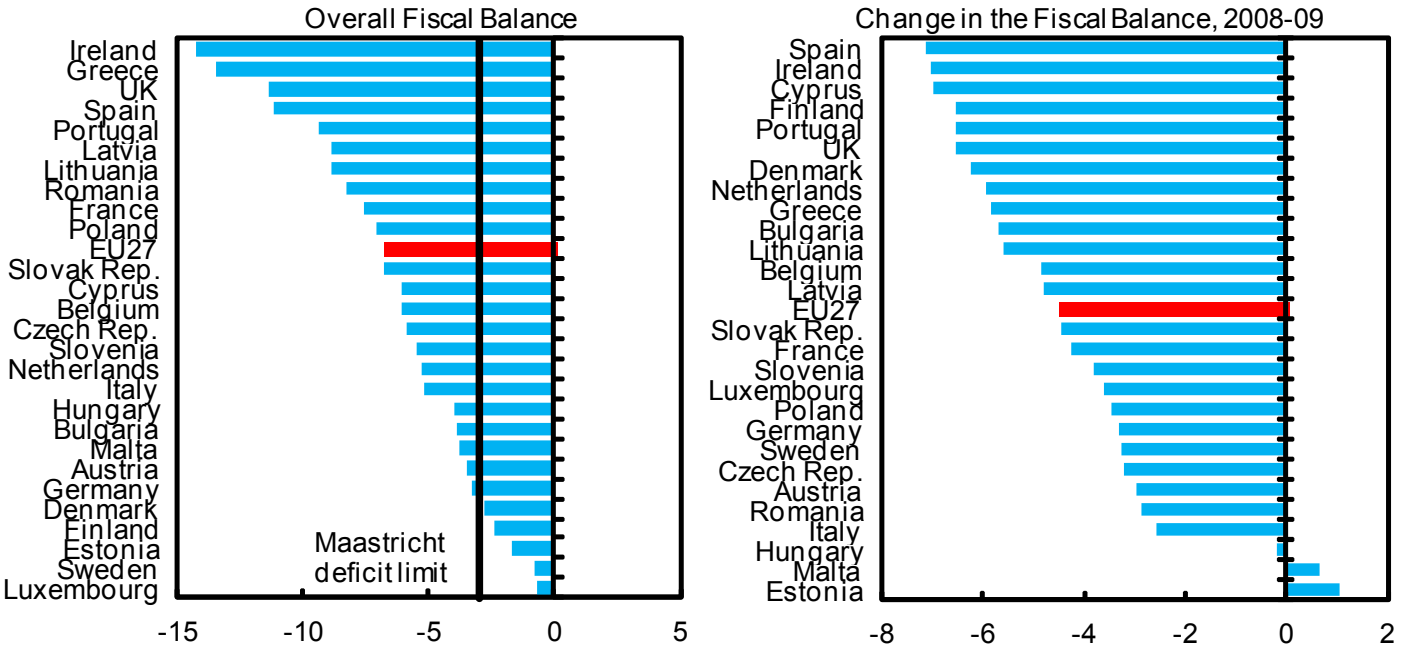

With some having more room than others to counter the cycle.
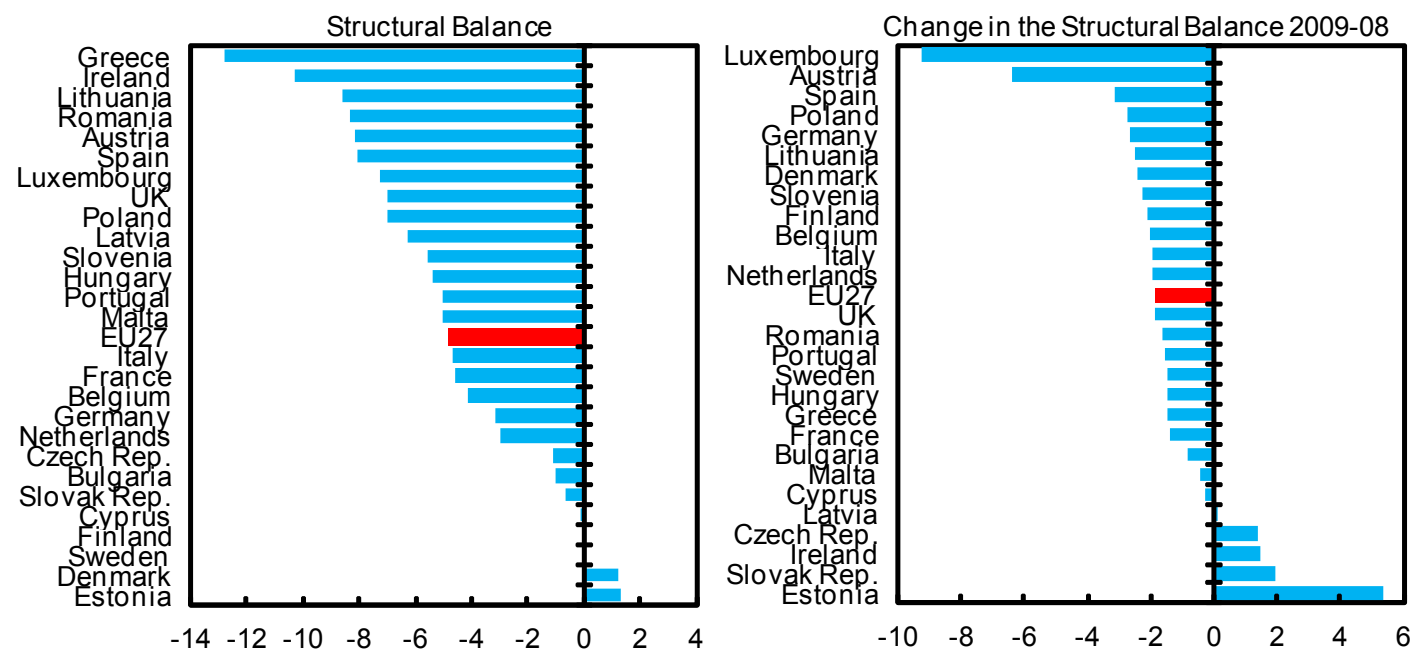

Sources: EUROSTAT; and IMF, World Economic Outlook. 
Figure 2. EU27: Population Projections
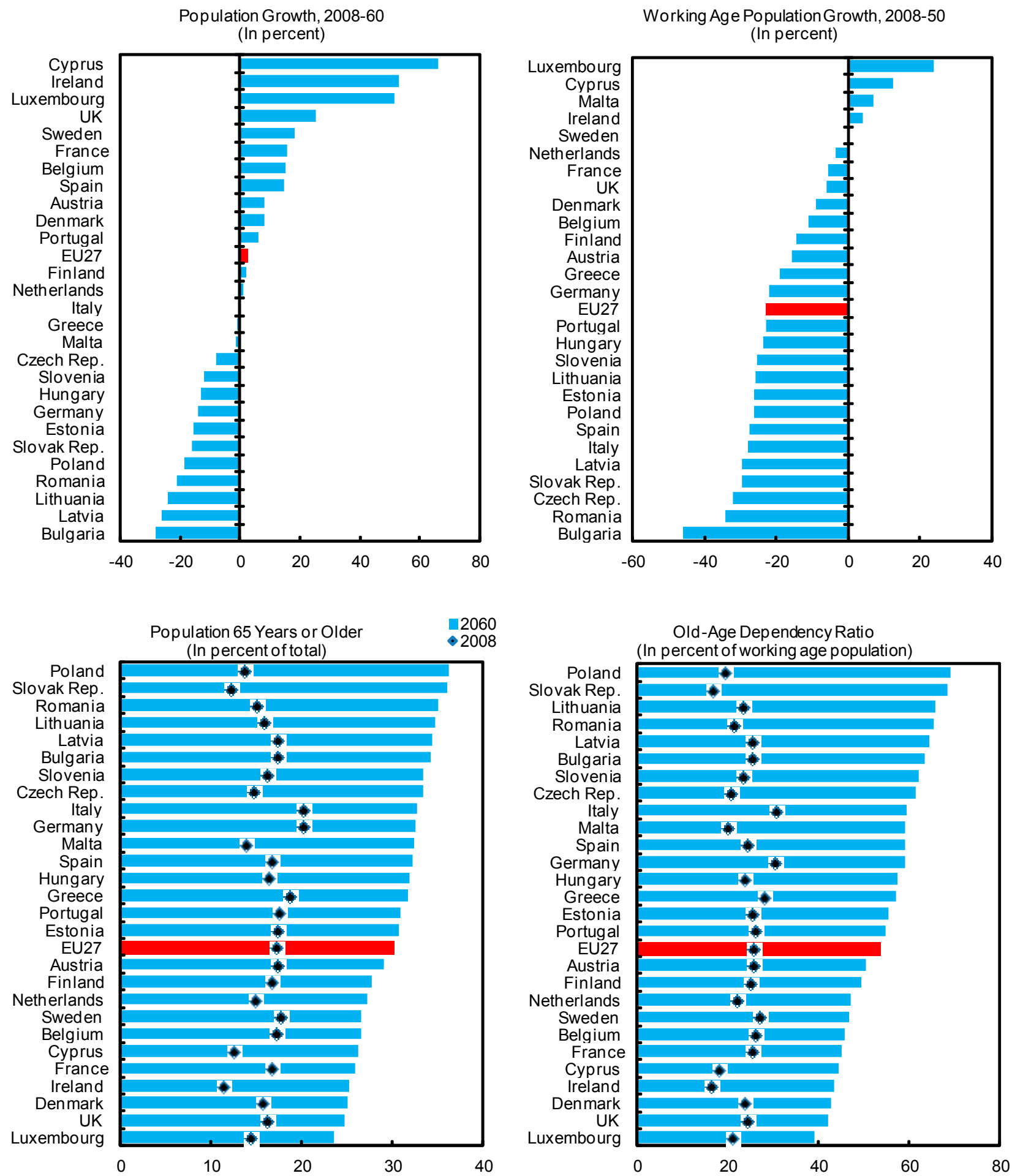

Source: Eurostat. 
Figure 3. European Commission Long-Term In dicators

(In percent of GDP)

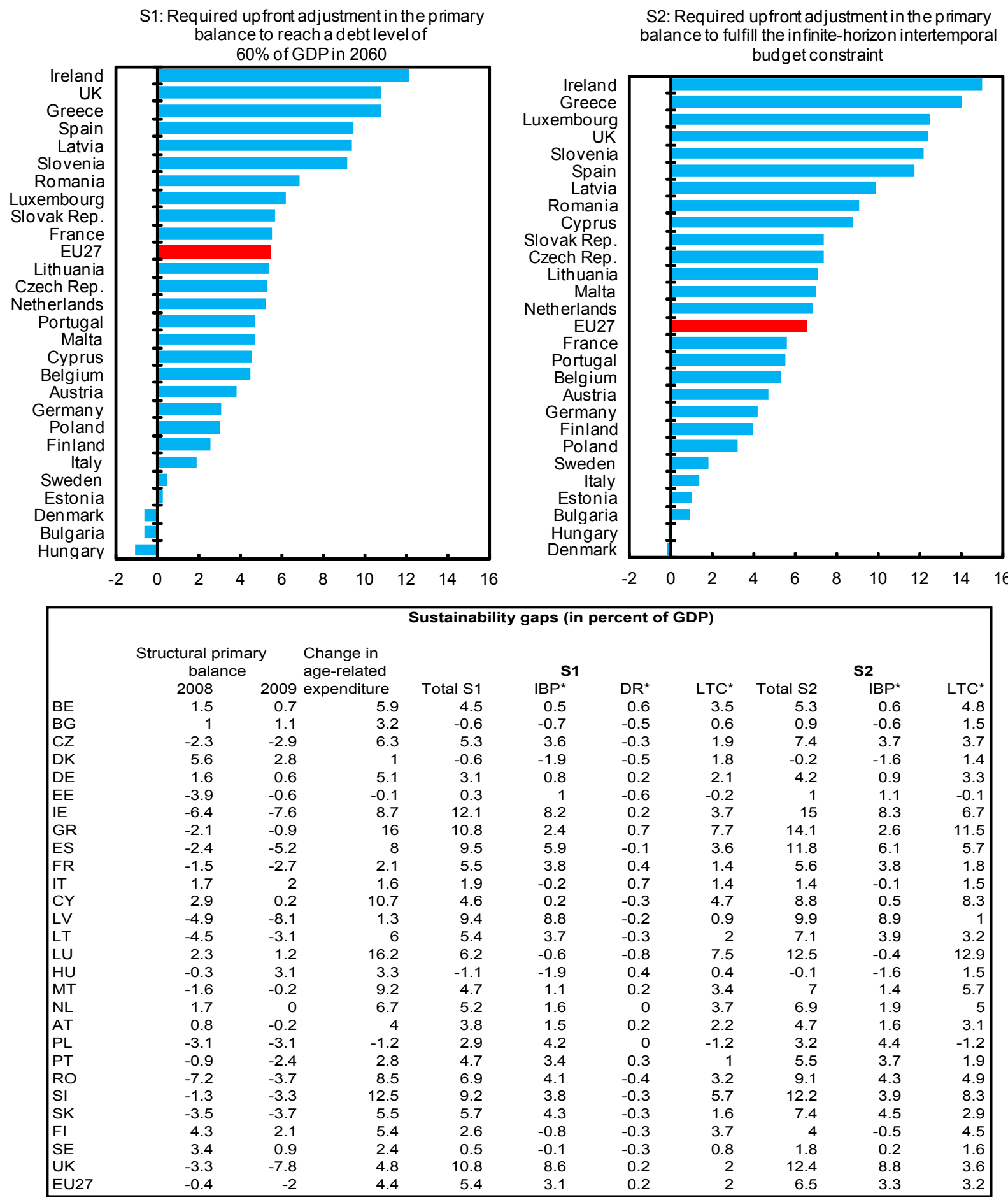

${ }^{*} \mathrm{IBP}=$ required adjustment given the initial budgetary position, DR = adjustment to reach the debt requirement (60\% of GDP) in 2060, LTC = required adjustment given the longterm change in the primary balance due to demographic ageing.

Source: European Commission, Sustainability Report 2009. 
For individual EU countries, traditional and comprehensive indicators can show different pictures (Figure 4). There is not necessarily a direct correspondence between the traditional debt and deficit measures and the more comprehensive indicators. Indeed, according to the comprehensive measures, some countries with relatively sound starting positions but large aging costs rank lower than countries with high current deficits, but that have lower future demographic costs, either due to less pronounced aging, or to comprehensive pension reforms. For example, Luxembourg, with one of the smallest deficits in 2009, ranks lower on comprehensive indicators than Poland and Lithuania, whose deficits topped 7 percent of GDP last year, but which reformed their pension systems significantly and early on. Hungary and Italy, with large debts, score much better on comprehensive indicators, again due to early pension reforms. This sometimes surprising reversal of order demonstrates that future aging implications can overwhelm the cost of the $2008-09$ crisis.

Figure 4. Traditional and Comprehensive Fiscal Indicators, 2009 (In percent of GDP)
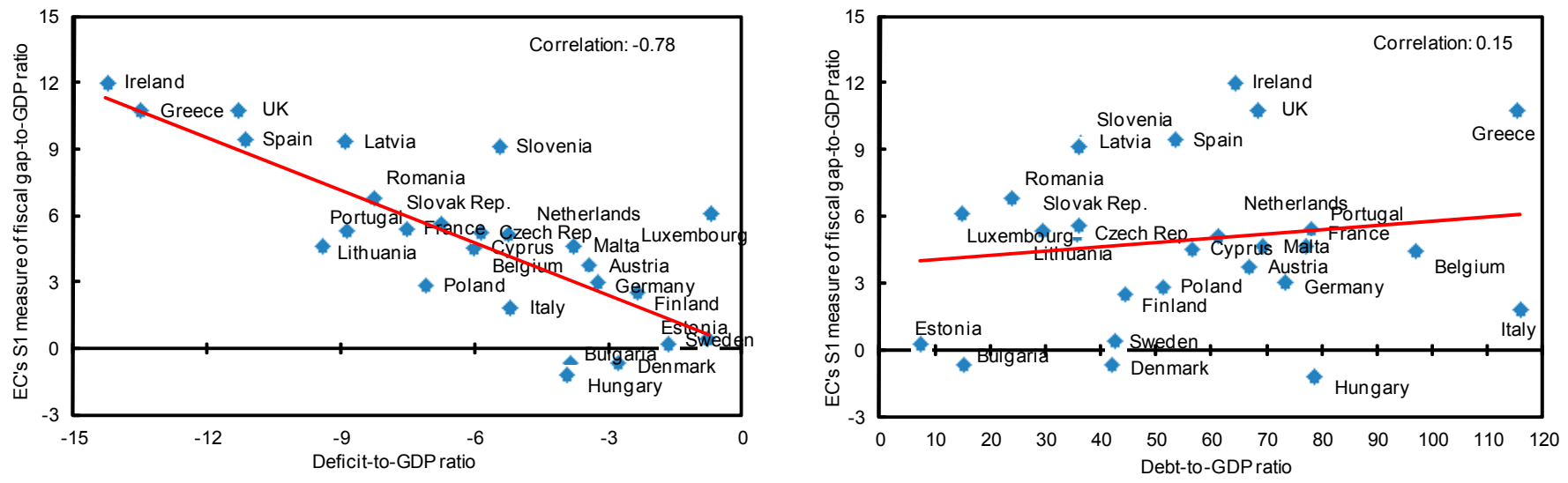

Sources: European Commission, 2009 Sustainability Report; Eurostat; and IMF staff cal culations.

\section{Measuring InTERTEMPoral Net WORTH}

Intertemporal net worth is calculated as the total of current net worth and the discounted sum of future primary balances under current policies. While current net worth can be easily derived using a traditional balance sheet, the forward-looking component requires projections that can span a finite or even an infinite-horizon. While infinite-horizon measures are theoretically more appealing, they can be harder to grasp and may prove weak from a policy point of view, as infinitehorizon budget constraints could be thought to be satisfied by very high levels of short-term debt and deficits, as long as there is reason to believe that sufficiently large primary surpluses will be achieved afterwards. Hence, finite-horizon indicators may prove more practical, if they can allow the long-run impact of population ageing to be analyzed in a meaningful way that is still within the sights of current taxpayers and policy makers. This section presents both infinite and finite horizon measures of intertemporal net worth, which are calculated either directly from the EC's indicatorsthe parametric approach — or using IMF staff's assumptions — comprehensive balance-sheet approach — as will be shown next. 


\section{A. The Parametric Approach}

Intertemporal net worth can be derived directly from the EC's Aging-Working Group indicators of fiscal sustainability (Mathematical Appendix and Box 1). As described earlier, the S2 indicator shows the permanent upfront adjustment required to satisfy the infinite-horizon intertemporal budget constraint, i.e. where current net debt and the discounted sum of primary surpluses cancel each other out over an infinite horizon. Given the above-mentioned definition of intertemporal net worth, it can be seen that there is a direct correspondence between it and S2. Similarly, a corresponding finite-horizon measure of intertemporal net worth can be derived directly from S1. While S1 relates to the adjustment required to reach debt to 60 percent of GDP in 2060, its finite-horizon intertemporal-net-worth correspondent reflects the total of current net worth and the sum of primary balances, discounted for a set period, but without requiring debt to reach the 60 percent-of-GDP limit. Intertemporal net worth measures can, therefore, be thought of as approximate "stock" correspondents of the S1 and S2 "flow" measures. Moreover, these indicators could have the advantage of relaying a potentially powerful message to the median voter: as mentioned earlier, while individuals may have trouble understanding what the S1 and S2 fiscal gap measures mean, it may be easier to bring home the notion that a large negative intertemporal net worth value, expressed in billions of Euros or percent of GDP, would be unsustainable and would need to be addressed urgently.

\section{Measures of intertemporal net worth constructed based on the S1 and S2 indicators paint a} bleak picture of the sustainability of Europe's public finances (Figure 5). The intertemporal net worth for the EU27 as a whole — which represents a weighted average of all EU27 countries - on current policies, stands at around negative 175 percent to of GDP (equivalent to $€ 20$ trillion) when measured over a 50-year horizon, and at 380 percent of GDP (or $€ 45$ trillion) over an infinite horizon, respectively. This is several times larger than conventional measures of the union's debt, which was estimated at 70 percent of GDP on a gross basis, and at 50 percent of GDP when financial assets are netted out.

Figure 5. Intertemporal Net Worth Derived from S1 and S2

(In percent of GDP)
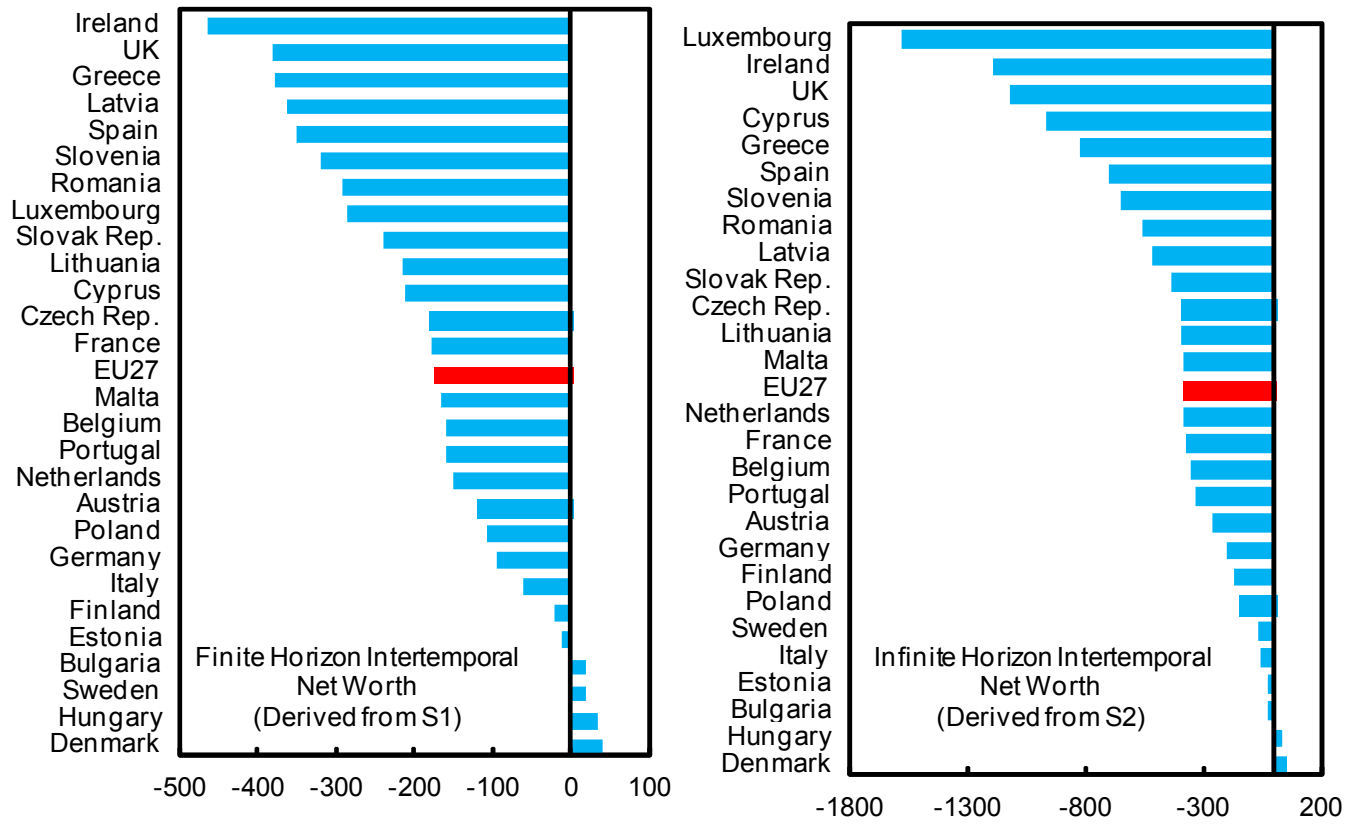

Source: IMF Staff estimates. 
The average measures mask important differences among EU27 countries (Figure 5). These arise due to large differences in starting fiscal positions and future aging burdens, as estimated by the EC in early 2009 (see the table in Figure 3 for individual-country estimates of initial structural balances and aging costs). On the one hand, only a few countries appear to be currently intertemporally sustainable: Hungary and Denmark under both measures, and Bulgaria and Sweden only under the finite-horizon definition. These countries combine both modest aging costs, due to early pension reforms, and a strong starting fiscal position. On the other hand, countries such as Greece, Cyprus, Luxembourg, and Slovenia have large negative net worth positions mainly due to high aging costs, while Ireland, the UK and Latvia are negatively affected by relatively worse initial fiscal positions.

Figure 6. Updated Intertemporal Net Worth Derived from S1 and S2 (In percent of GDP)
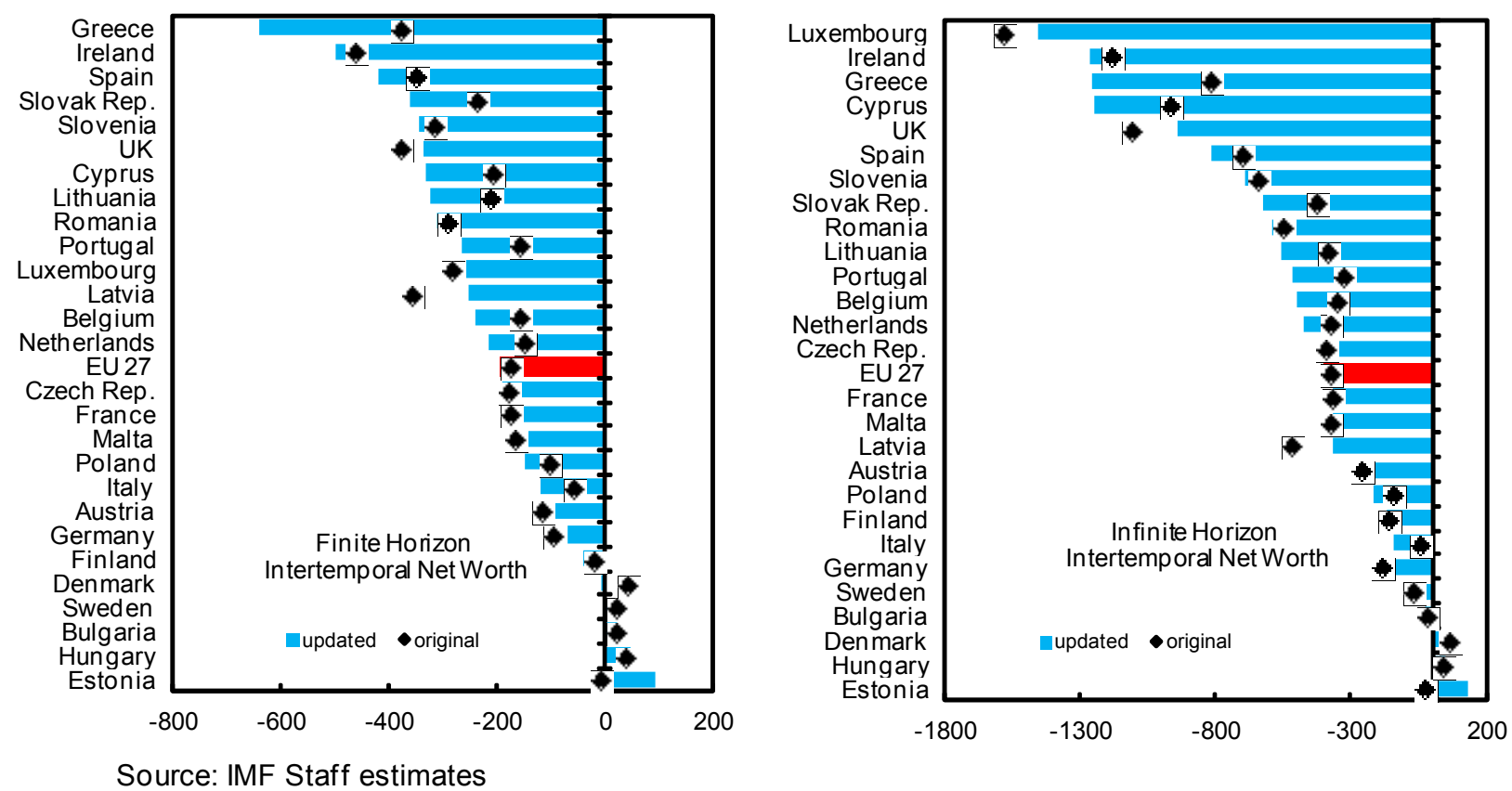

These results broadly hold up when data are updated to reflect more recent information, though some countries' ranking changes (Figure 6). The calculations of intertemporal net worth derived from the EC's S1 and S2 indicators implicitly take on board all underlying assumptions as of the time these indicators were derived. Of particular importance are the estimated 2009 primary structural balances, which correspond to the value of the primary balances under current policies after removing the effect of the cycle and of one-off measures. Large uncertainties usually surround these estimates, related to difficulties in estimating the output gap and budget elasticities. Moreover, as they were derived in early 2009 , they may not fully capture more recent events. The parametric approach allows for updating the calculation of intertemporal net worth with new initial values for debt, public sector financial assets, and the primary structural balance (see Mathematical Appendix for the algebraic expressions). Including more recent developments during the 2009 global crisis results in a modest increase in the initial structural balance and debt for the EU27 average, which implies that its intertemporal net worth worsens slightly - to 192/398 percent of GDP under the finite/infinite horizon measures - but the measures for individual countries, and hence their relative ranking, can change significantly. For example, including the significant revisions to the 2009 deficit and debt data that became available in early 2010, which reflected more fully the effects of 
actual rather than projected fiscal policies in 2009, finite intertemporal net worth worsens by more than 100 percent of GDP in Greece, the Slovak Republic, and Cyprus, while it improves by about the same amount in Estonia and Latvia.

\section{Box 1. Estimating Intertemporal Net Worth from the EC's S1 and S2 Indicators-A Shortcut}

It can be shown that a direct correspondence exists between the EC's S1 and S2 indicators and measures of intertemporal net worth (see Mathematical Appendix):

$$
\text { inw } w_{t}=-S 2_{t_{0}} \cdot \sum_{t=t_{0}}^{\infty} \delta_{t}+a_{t} \quad \quad \text { inw } w_{t}^{*}=-S 1_{t_{0}} \cdot \sum_{t=t_{0}}^{2060-t_{0}} \delta_{t}-60 \cdot \delta_{2060}+a_{t}
$$

where inw and inw* represent intertemporal net worth in percent of GDP under an infinite and finite horizon, respectively, $\mathrm{a}_{\mathrm{t}}$ represents the initial assets of the public sector in percent of GDP, and $\delta_{\mathrm{t}}$ is the time-varying discount rate that depends on real growth and the real interest rate.

Practically, to calculate inw from S1 and S2, the variable yearly-profile of the EC's projected real growth is needed to compute the variable discount rate (the real interest rate is assumed constant at 3 percent). ${ }^{1}$ However, for most EU27 countries, measures of inw can also be approximated directly from the published figures for S1, S2, and their subcomponents, and the EC's estimates of the 2010 debt $\left(\mathrm{d}_{2010}\right)$ and the 2009 primary structural balance $\left(\mathrm{pb}_{2009}\right)$, without the need for growth projections. ${ }^{2}$ To do so, recall that:

$$
\begin{gathered}
\mathrm{S} 1=\mathrm{IBP}_{\mathrm{S} 1}+\mathrm{DR}+\mathrm{LTC} \text { and } \\
\mathrm{S} 2=\mathrm{IBP}_{\mathrm{S} 2}+\mathrm{LTC}
\end{gathered}
$$

,where IBP is the required adjustment given the initial budgetary position (i.e. the gap between the current structural primary balance and the long-term debt stabilizing balance), LTC is the required adjustment given the long-term change in the fiscal position due to aging, and DR is the adjustment needed to reach a debt of 60 percent of GDP by 2060. Given these definitions, it can be shown that, for the countries mentioned above:

$$
\begin{gathered}
i n w \approx-S 2 \frac{d_{2010}}{I B P_{S 2}+p b_{2009}}+a_{2010} \\
\text { inw }^{*} \approx \frac{d_{2010}}{D R \cdot d_{2010}+\left(I B P_{S 1}+p b_{2009}\right)\left(d_{2010}-60\right)}\left[\left(d_{2010}-60+D R\right) S 1-60 \cdot D R\right]+a_{2010}
\end{gathered}
$$

These approximations can be helpful in quickly transforming the S1 and S2 indicators into measures of intertemporal net worth than may be conveyed to the median voter more easily. These expressions can also be used to update the intertemporal net worth measures with more recent data on debt and the primary deficit.

Also, the current value of public assets is required, though this is readily available from Eurostat.

${ }^{2}$ These approximations do not hold for Denmark, Lithuania, Luxembourg, the Netherlands, Finland and Slovenia, because of large projected long-term changes in property income, which affect the IBP and the S1 and S2 indicators. In all other countries, these changes are small and, for simplicity, can be ignored. 


\section{B. The Comprehensive Balance-Sheet Approach}

\section{Measures of intertemporal net worth for each EU country can also be derived using the} comprehensive balance-sheet approach. This approach has the advantage of allowing for using Fund staff projections for the medium-run path of macroeconomic variables. In particular, it allows for an explicit medium-term fiscal path that can take into account adopted/planned future fiscal measures, rather than relying exclusively on an estimated measure of the current structural fiscal balance, which can be difficult to estimate. It is also a more transparent framework, as it builds on the traditional balance sheet, which again can be easier to understand by the public. The comprehensive balance sheet can be derived straightforwardly, in three steps.

In a first step, a traditional (backward-looking) accounting balance needs to be computed for each country. The difference between a country's public sector financial assets and liabilities constitutes its current financial net worth. A more comprehensive measure of current net worth would also include the public sector's net capital stock - the sum of all buildings, highways, infrastructure, and land acquired by the state over the years. However, in the absence of data on this stock for all EU27 countries, and for comparability purposes, only financial assets and liabilities are considered here, with financial net worth thus likely to underestimate total net worth. ${ }^{11}$ Taking the EU27 as a whole as an illustrative example, its traditional balance sheet (available directly in Eurostat) reveals that its financial net worth has recently been deteriorating, reaching negative 47 percent of GDP in 2009 , or about $€ 5.5$ trillion (Table 1). ${ }^{12}$

Table 1. EU27: Traditional Balance Sheet, 2005-09 (In percent of GDP)

\begin{tabular}{lrrrrr}
\hline & 2005 & 2006 & 2007 & 2008 & 2009 \\
\hline Financial assets & $\mathbf{2 8}$ & $\mathbf{2 9}$ & $\mathbf{2 9}$ & $\mathbf{3 0}$ & $\mathbf{3 4}$ \\
Currency and deposits & 5 & 5 & 5 & 6 & 6 \\
Securities other than shares & 2 & 2 & 2 & 2 & 3 \\
Loans & 3 & 3 & 3 & 3 & 4 \\
Shares and other equity & 13 & 14 & 14 & 13 & 15 \\
Other financial assets & 5 & 5 & 5 & 5 & 6 \\
Liabilities & $\mathbf{7 0}$ & $\mathbf{6 7}$ & $\mathbf{6 4}$ & $\mathbf{6 8}$ & $\mathbf{8 1}$ \\
Currency and deposits & 4 & 4 & 3 & 3 & 4 \\
Securities other than shares & 54 & 51 & 48 & 52 & 63 \\
Loans & 10 & 10 & 9 & 9 & 10 \\
Other liabilities & 3 & 3 & 3 & 3 & 4 \\
Financial net worth & $-\mathbf{4 2}$ & -39 & $-\mathbf{3 5}$ & $\mathbf{- 3 8}$ & $-\mathbf{4 7}$ \\
\hline
\end{tabular}

Sources: Eurostat; and IMFstaff estimates.

\footnotetext{
${ }^{11}$ For some countries, estimates of government net capital stocks for 1960-2001 have been calculated by Kamps (2004). These could be added to financial assets to calculate the comprehensive net worth of these countries. This has not been done here, to maintain consistency across all countries.

${ }^{12}$ Of course, it is already striking in a traditional balance sheet sense that the EU27 has such a large negative net worth even before counting the prospective costs of aging.
} 
In a second step, a country-specific long-term fiscal outlook is developed based on a set of long-run macroeconomic projections. Here, medium-term GDP, labor market, and fiscal projections generally correspond to the Spring 2010 IMF WEO outlook for $2009-15 .{ }^{13}$ For example, for the EU27, growth is assumed to gradually recover and reach 2 percent by 2015, while the overall fiscal deficit is projected to fall to about 2 percent of GDP. Long-run GDP and labor market projections converge to the EC's assumptions, which take into account country-specific demographic projections, as presented in the 2009 Sustainability Report (Figure 7). For the union as a whole, average GDP growth is projected to decline to 1.5 percent by 2060 and stabilize at that level thereafter. The GDP deflator growth is assumed to converge to the ECB's target of 2 percent, and the real interest rate is projected to be 100 basis points above real growth in the long run. ${ }^{14}$ All non-age, non-interest related fiscal revenues and expenditures, as well as financial assets and other financial liabilities except for public debt are assumed to remain constant in percent of GDP from 2015 onward. Net aging-related incremental expenditures are also taken from the Sustainability Report, which are estimated at 4.4 percent of GDP for the EU27 for 2010-60 (Figure 8). ${ }^{15}$

In a third and final step, the comprehensive balance sheet is constructed combining steps one and two above. The stream of projected primary balances under current policies is discounted using the nominal interest rate on debt. As before, two measures are constructed: one that discounts primary balances over a 50-year horizon and a second one that assumes an infinite horizon. The net present values are then added to the current net worth, obtaining both an infinite and a finite-horizon measure of a country's intertemporal net worth. This exercise can be repeated for successive years during the medium-term, including as new information comes in, to gauge whether the intertemporal net worth is improving or worsening over time on current policies.

For the EU27, intertemporal net worth is negative, large, and deteriorating over the medium term (Table 2). For the EU27, the 2010 intertemporal net worth is negative 150 or 470 percent of GDP (equivalent to close to $€ 20$ or 60 trillion), depending on the horizon of the measure, or three/ten times larger than current financial net worth. These results are broadly in line with the picture obtained from the EC's indicators discussed earlier, although some of the assumptions are different, and importantly, the medium-term macroeconomic and fiscal profile has been updated to take into account more recent information. Moreover, the intertemporal net worth of the EU27 is slowly deteriorating over time. This implies that current policies are moving in the "wrong direction" at the area aggregate level, and that more ambitious policies are required to change the dynamics of the EU27's intertemporal net worth to eliminate the existing sustainability gap.

\footnotetext{
${ }^{13}$ Fiscal data for the Slovak Republic have been updated to reflect the 2009 Eurostat revision. For Cyprus, fiscal data was revised to take into account additional announced measures. For Germany, fiscal data differs from the WEO in that it does not assume additional measures beyond the withdrawal of the fiscal stimulus (passive scenario). For Latvia and Hungary, WEO data assume additional (unidentified) fiscal measures to comply with the current IMF program in place.

${ }^{14}$ Specifically, real GDP growth after 2015 is assumed to gradually converge to the EC's estimated value by 2025 and to follow the path estimated by the Commission thereafter. The deflator and the real interest rate are equally assumed to gradually converge by 2025 to their respective long-run values. A drawback of this methodology is that it does not consider the general equilibrium effects of assumed policies on macroeconomic variables, such as potentially higher interest rates due to larger deficits and debt, as this paper only undertakes a counterfactual thought experiment rather than a general equilibrium simulation. Here, the interest rate, which is variable, functions primarily as a discount rate.

15 The EC's estimates of aging costs represent some of the most comprehensive and comparable estimates that the author is aware of. However, they also have drawbacks (see Franco et. al., 2005, Langenus, 2006), including with respect to the baseline estimates of health care costs, which may be too optimistic (see IMF, 2010).
} 
Figure 7. EU27: Long-Run Macroeconomic Projections
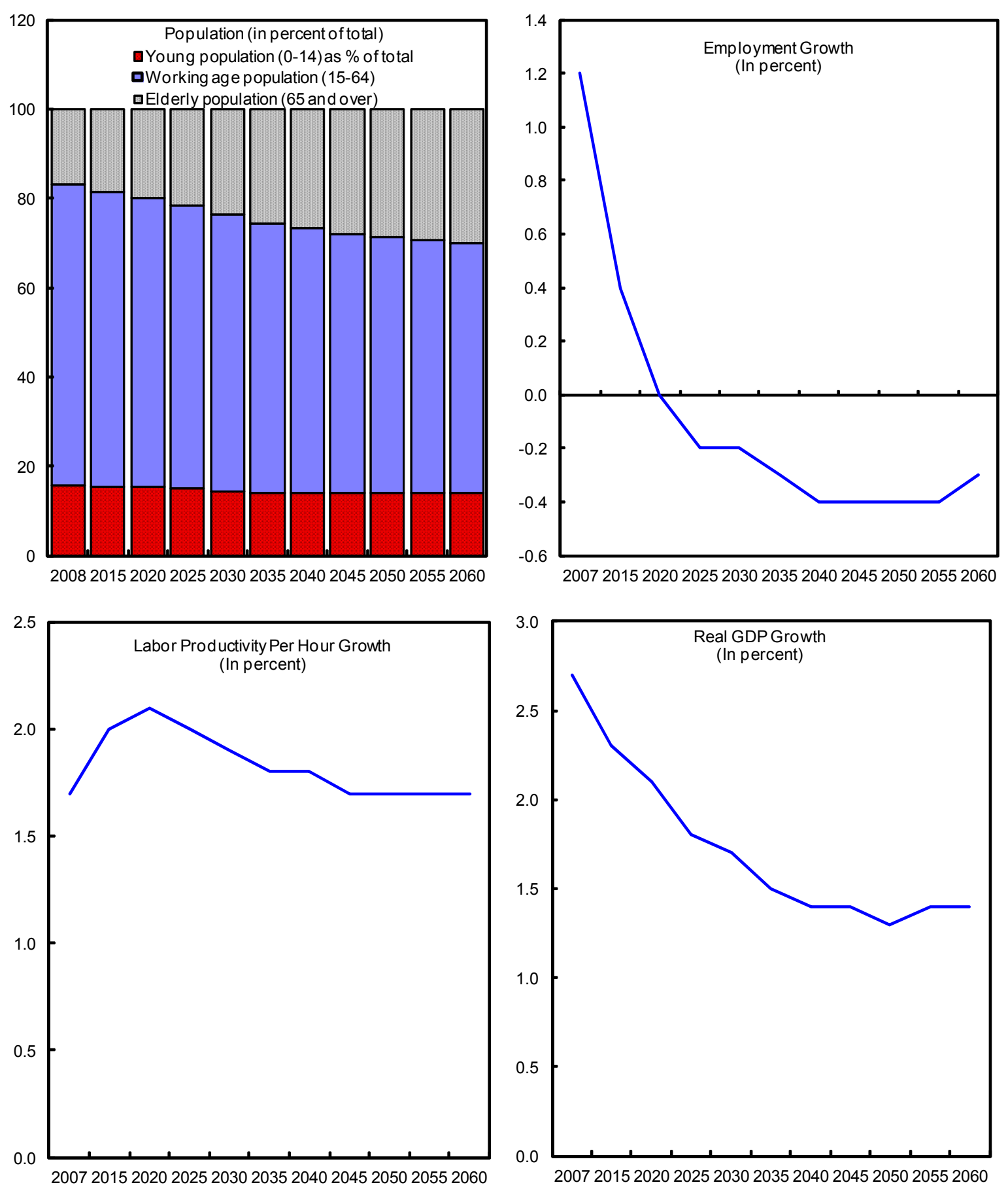

Sources: IMF Spring 2010 WEO and European Commission. 
Figure 8. EU27: Long-Run Fiscal Projections

(In percent of GDP, unless otherwise specified)
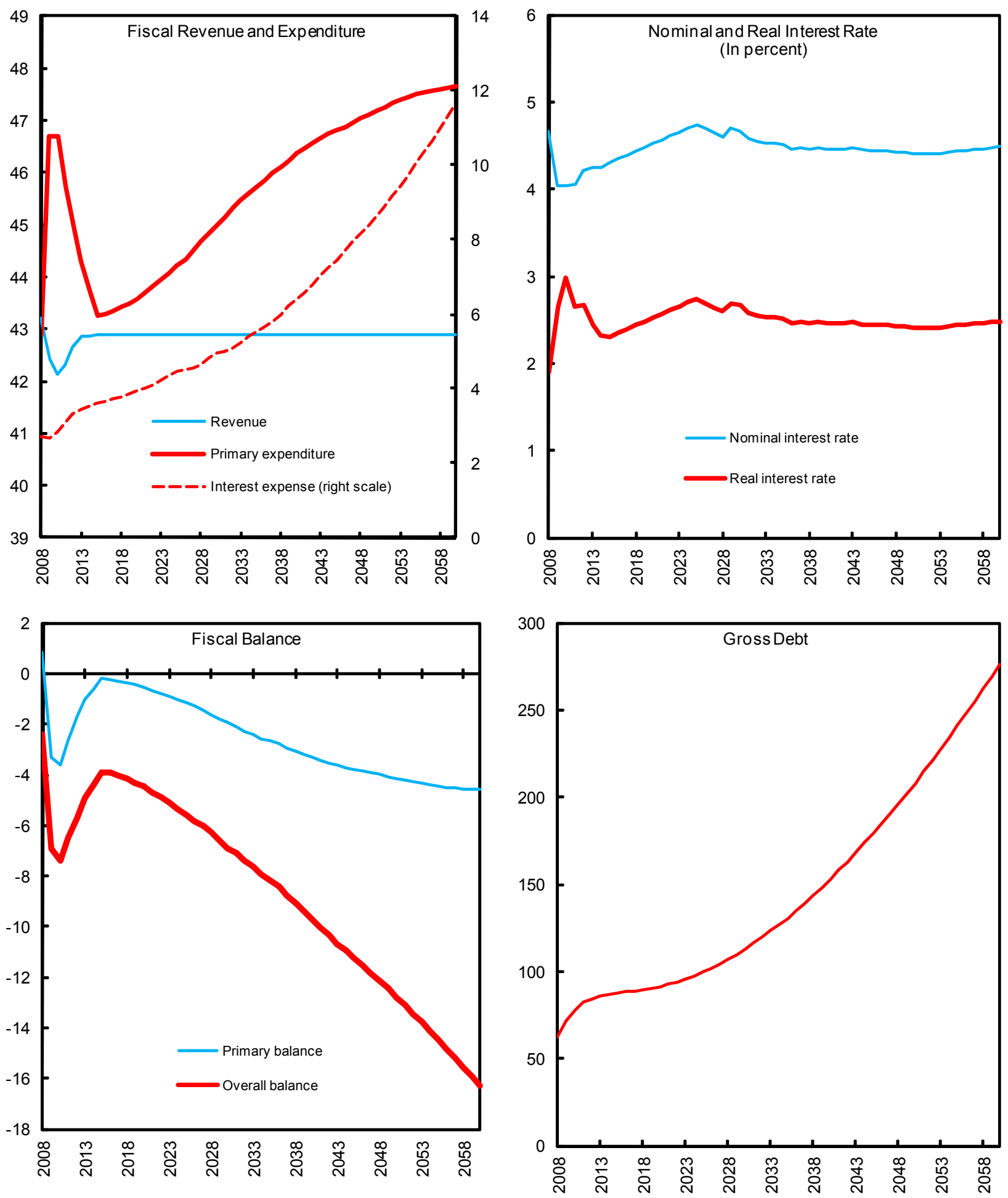

Sources: Spring 2010 IMF WEO and IMF Staff calculations. 
Table 2. EU27: Public Sector Comprehensive Balance Sheet, 2009-15

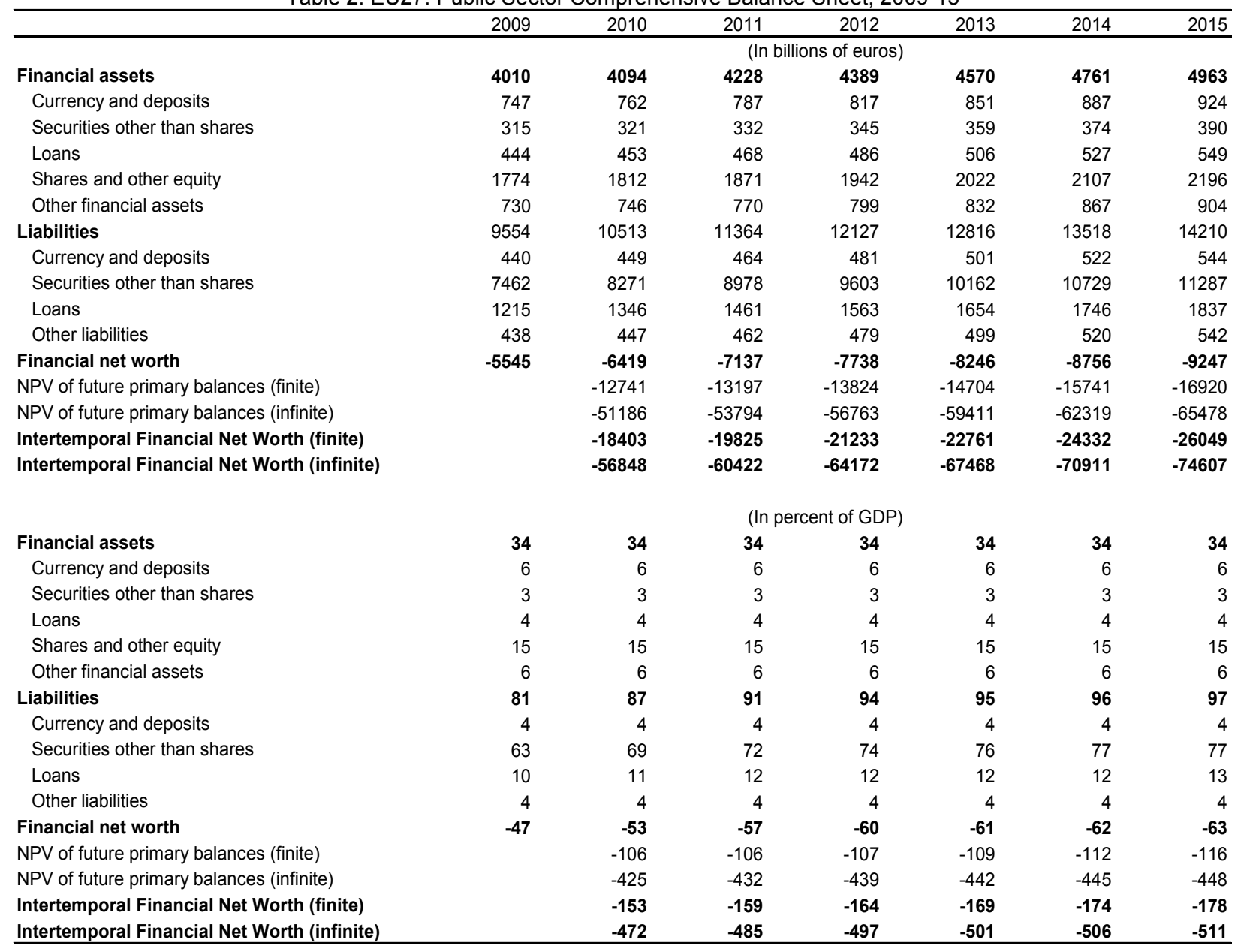

Sources: Eurostat; and IMFstaff estimates.

The disparity among countries remains large (Figure 9). On the one hand, the new data captures significant fiscal adjustments planned in the UK, Latvia, and Ireland over the medium term, which are expected to dramatically improve their net worth position compared to the initial implicit estimates based on the EC's numbers. On the other hand, a deterioration in the initial fiscal position and insufficient consolidation over the medium term in countries such as Greece, Cyprus and Luxembourg, combined with their very high aging costs, results in a significant worsening of their intertemporal net worth much beyond the level underlying the Commission's calculations (the bubble graph in Figure 9 indicates how intertemporal net worth is affected by the initial fiscal position and the long-run aging costs in various countries). ${ }^{16}$

\footnotetext{
${ }^{16}$ For Bulgaria, the intertemporal net worth gap is likely underestimated, as the 2009 deficit does not take into account the large cash-accrual upward revision (from 1.9\% of GDP to 3.9\%), and aging costs do not include recent measures, including the Swiss indexation rule, increases in minimum and maximum pensions in 2009, and a reduction of pension contributions from 22 percent to 16 percent during 2009-2010. For Greece, Portugal and Spain, fiscal data do not include measures announced after April 2010.
} 
Figure 9. Intertemporal Net Worth Derived from the Balance Sheet Approach (In percent of GDP)
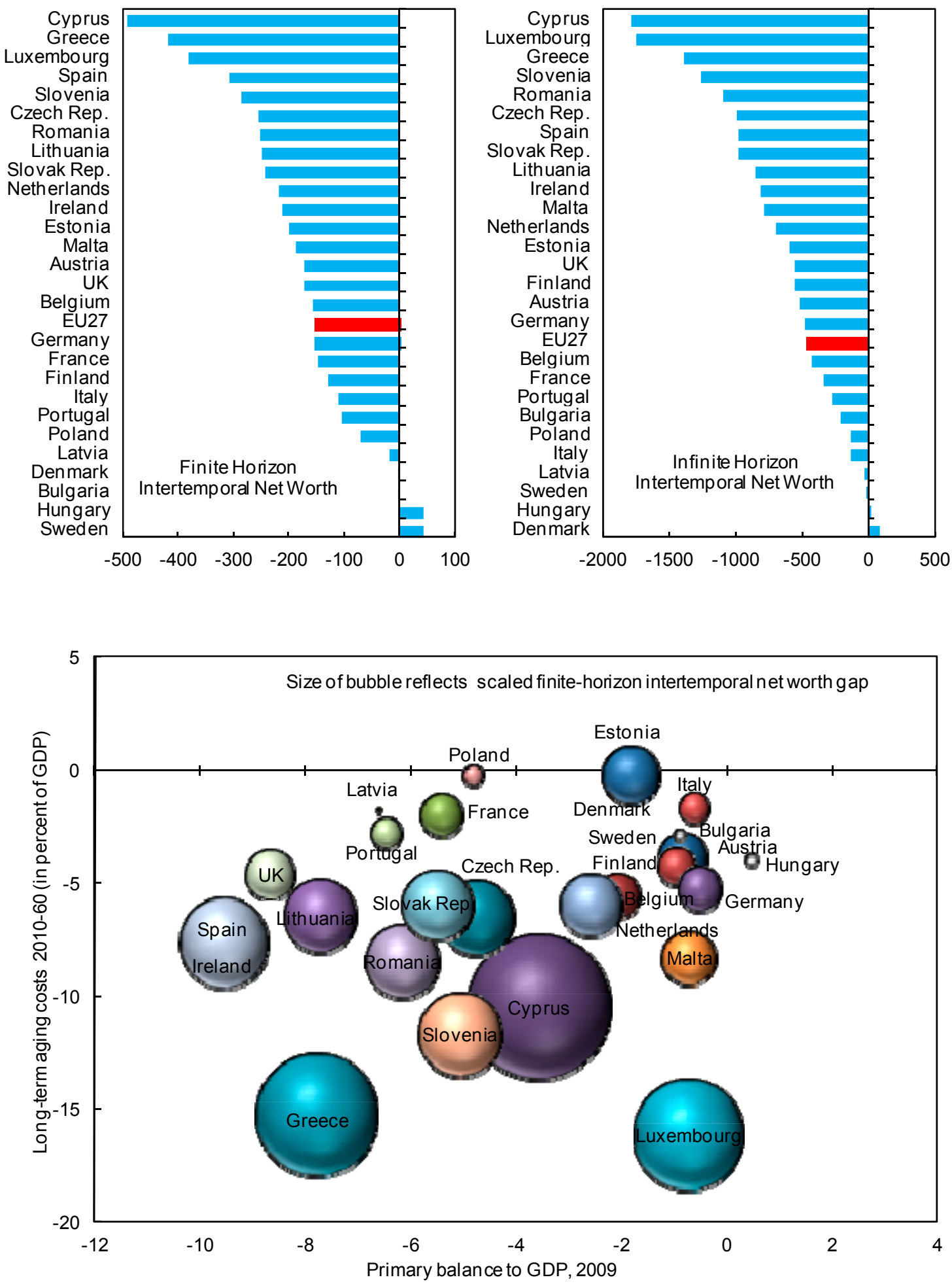

Source: IMF staff estimates. 


\section{Generally, most Emerging European countries fare much better than some advanced} counterparts on measures of intertemporal net worth. In the case of Eastern Europe, this may appear somewhat counterintuitive, given that this region is expected to experience more acute population aging than in the rest of Europe, with old age dependency ratios exceeding 50-60 percent by 2060 in countries such as Poland, Lithuania, and Latvia (recall Figure 2). However, it is precisely these countries that have undertaken significant pension reforms, in large part as a response to the aging problems they face. Public social security pension systems have been (partly) switched into funded private defined-contribution schemes in Hungary (1997), Sweden (1999), Poland (1999), Latvia (2001), Estonia (2002), Lithuania (2004), Slovakia (2005), and Romania (2007), with only the Czech Republic, Slovenia and Bulgaria failing to do so. Moreover, Poland, Germany, Slovakia, and the Netherlands undertook reforms that tightened early retirement. Finally, reforms that switched public pension systems from defined-benefit into notional definedcontribution schemes have been undertaken in Italy (1995), Latvia (1996), Sweden (1999) and Poland (1999). ${ }^{17}$ Aging costs estimated by the European Commission take into account not only population aging, but also the effects of pension reforms. As a result, there is a direct correspondence between reforms and low values of the shortfall in intertemporal net worth. Studies that aim to construct forward-looking fiscal measures that focus on dependency ratios, but which do not account for the effects of the reforms could thus lead to flawed results. ${ }^{18}$

\section{Sensitivity Analysis}

\section{Varying the assumptions can lead to changes in the point estimates obtained, though the} qualitative message remains unchanged (Table 3 ). This is already clear from the comparison of results obtained from the two different methodologies used in this paper. The parametric approach leads to a lower value of intertemporal net worth for the EU27 in an infinite horizon mainly because the assumption of a constant real interest rate of 3 percent, implying a higher interest-growth differential compared to that assumed in the balance sheet approach, essentially lowers the value of the discount rate used in the NPV calculations (the discount rate is relatively more predominant at the longer-term horizon, as shown in Table 3). On the other hand, the balance-sheet approach leads to a lower value of intertemporal net worth at the finite horizon compared to the parametric approach, because it encompasses a more explicit and ambitious medium-term fiscal adjustment that leads to lower primary balances - this effect dominates at the finite horizon, as medium-term developments weigh more in the NPV calculation (Table 3). For simplicity, both methodologies rely on common estimates for long-run aging costs. However, should future health-care costs be under-projected, or pension costs rise faster in the future due to possible pressures resulting from low replacement rates, then intertemporal net worth would be correspondingly worse. ${ }^{19}$

\footnotetext{
${ }^{17}$ Systems close to this principle include "wage points," as known, for example, in Germany and France. See Draxler (2009) for more details.

${ }^{18}$ For example, Gokhale (2009) finds that Poland's fiscal imbalance is a whopping -1,500 percent of GDP, mainly because the analysis does not appear to include the effects of pension reforms on future aging costs.

${ }^{19}$ See Annex II of the 2009 Aging Report, which presents alternative health care cost projections suggesting that such costs could be higher by an average of 4.5 percent of GDP relative to the baseline for the EU27. This point has also been emphasized by recent IMF papers (see IMF, 2010).
} 
Table 3. EU27: Sensitivity Analysis, Intertemporal Net Worth (percent deviation from baseline)

\begin{tabular}{lrr}
\hline & Finite horizon & Infinite horizon \\
\hline $\mathrm{r}-\mathrm{g}=2$ & -12.7 & -48.5 \\
$\mathrm{r}=3$ & -5.9 & -32.2 \\
& & \\
LR primary deficit higher by 1 ppt & 22.0 & 21.8 \\
LR primary deficit lower by 1 ppt & -20.9 & -21.5 \\
& & \\
MT primary deficit higher by 1 ppt & 27.3 & 23.5 \\
MT primary deficit lower by 1 ppt & -25.2 & -22.9 \\
\hline
\end{tabular}

Source: IMF staff estimates.

These indicators should be interpreted with some caution and be updated regularly. While traditional indicators can be more readily measured according to well-established methodologies, the comprehensive public sector balance sheet and resulting measures of intertemporal net worth are based on a series of assumptions and long-run projections that are subject to uncertainty.

Reassuringly, the results obtained here using two different methodologies and different mediumterm macroeconomic and fiscal assumptions are similar, especially for the EU27 as a whole. They are somewhat lower than the results obtained by Gokhale (2009), who finds that the EU-25's average finite-horizon fiscal imbalance was 435 percent of 2004 GDP, though this latter analysis is based on data as of 2005 and does not incorporate the long-run effects of pension reforms in many countries. Still, what should be emphasized when using these indicators is not as much the precise point value obtained, but rather their sign, order of magnitude, and the direction in which they are evolving over time as a result of economic developments and national policies.

\section{Policy Implications}

A relatively small upfront but permanent improvement in the primary fiscal balance can go a long way in reducing the shortfall in intertemporal net worth (Figure 10). The magnitude of the improvement needed to bring intertemporal net worth toward positive territory in each individual country depends on the level of its intertemporal imbalance, but also on its growth prospects over time. A simple calculation can be made to see how much a one percent of GDP permanent upfront improvement in the primary balance in 2010 would yield in NPV terms over the long run, ceteris paribus, by compounding the one percent amount by the time-varying discount rate, which takes into account country-specific GDP growth rates and the corresponding variable interest rate. Generally, countries which expect to benefit from a relatively higher growth profile and lower interest rate, especially in the near term, tend to benefit relatively more from a one percent fiscal adjustment compared to those countries whose growth prospects are weaker and which confront higher interest rates. ${ }^{20}$ For the EU27, a one percent permanent improvement now would yield about

\footnotetext{
${ }^{20}$ Again, this is a counterfactual thought experiment which does not take into account the general-equilibrium feedback effects from fiscal consolidation to growth and interest rates.
} 
45/120 percent of GDP in net present value terms over a finite/infinite horizon. This reveals that a realistic, non-excessive fiscal effort undertaken now can have much larger benefits in the long run.

Figure 10. Long-Term Gains from a One Percent Upfront

Permanent Fiscal Adjustment (in percent of GDP)

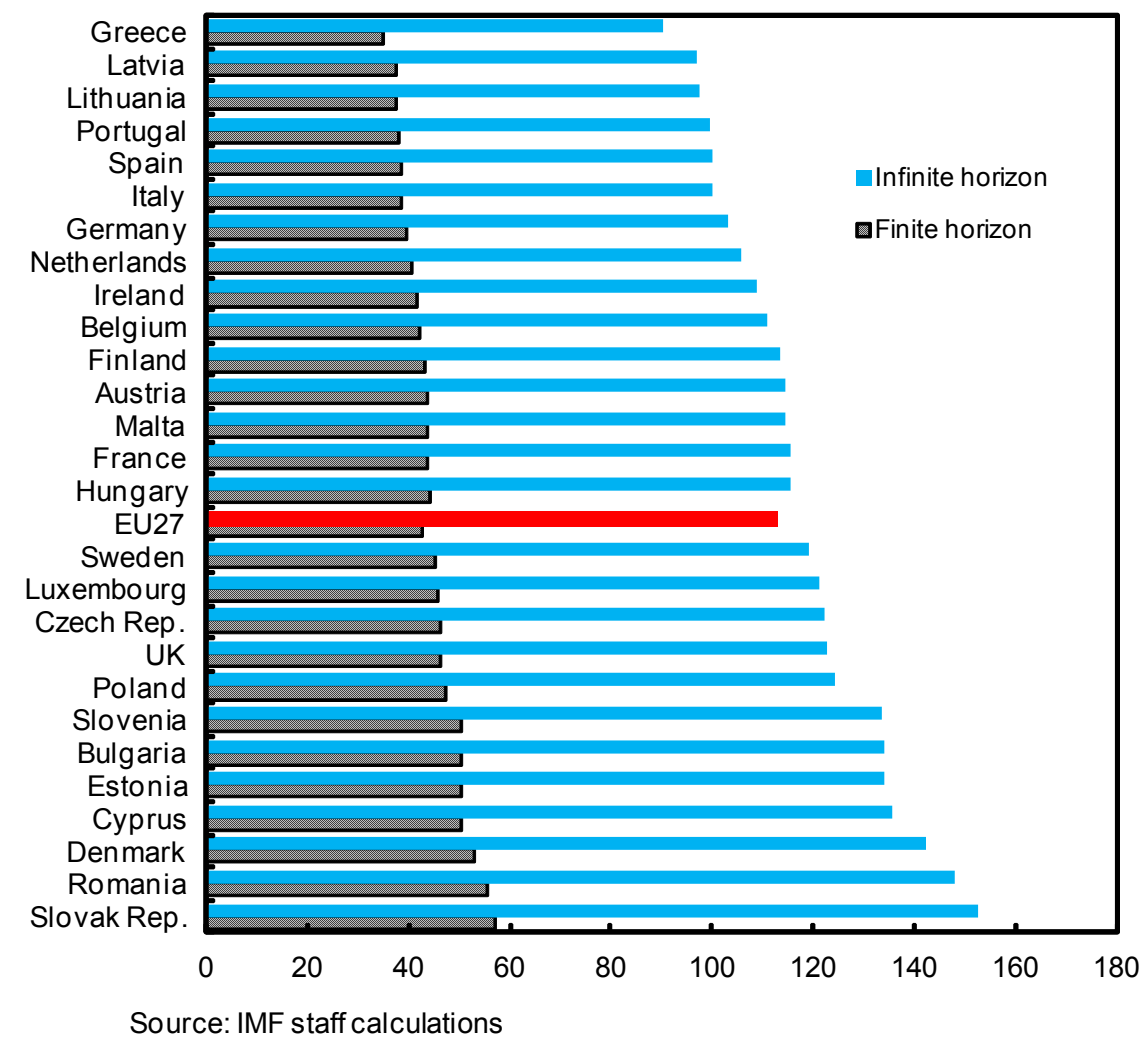

For most countries, the fiscal effort required to satisfy the Maastricht deficit criterion by 2012 would be insufficient to eliminate the intertemporal net worth gap (Table 4). The new estimates of the gaps in intertemporal net worth, together with the exercise above calculating the yield of a one percent fiscal adjustment can, in turn, be used to derive S1- and S2-like intertemporal fiscal gap indicators (which simply equal the total intertemporal net worth gap divided by the yield from a one percent adjustment). These measures essentially indicate the required upfront fiscal adjustment required to bring intertemporal net worth to zero (thus satisfying the intertemporal budget constraint) over a finite or infinite time horizon. These estimates can be easily compared to the upfront permanent adjustments that would be required under the Maastricht treaty (deficit gap) to bring the headline deficit to 3 percent of GDP by 2012. Importantly, in many EU27 countries, the IMF-staff forecasted requirement needed to bring the deficit to the Maastricht limit by 2012 would be insufficient to make the fiscal position sustainable, especially at the infinite-horizon.

Interestingly, for a few countries (Denmark, Hungary, Poland, Portugal, and the UK), under the baseline assumptions, achieving a deficit of 3 percent of GDP by 2012 could be more than sufficient to ensure that intertemporal net worth is equal or greater than zero. For the area as a whole, in addition to an upfront permanent effort of about 2.7 percent of GDP to bring the deficit to 3 percent of GDP by 2012, additional measures of at least 1-1.5 percent of GDP would be required to also bring intertemporal net worth into balance. 
Table 4. Intertemporal Net Worth (Balance Sheet Approach), and Required Upfront Adjustment to Bring Net Worth Into Balance or the Deficit to 3 percent of GDP by 2012 (in percent of GDP)

\begin{tabular}{|c|c|c|c|c|c|}
\hline & $\begin{array}{c}\text { Finite } \\
\text { Intertemporal } \\
\text { Net Worth }\end{array}$ & $\begin{array}{c}\text { Infinite } \\
\text { Intertemporal } \\
\text { Net Worth }\end{array}$ & $\begin{array}{l}\text { Intertemporal } \\
\text { gap, finite }\end{array}$ & $\begin{array}{l}\text { Intertemporal } \\
\text { gap, infinite }\end{array}$ & $\begin{array}{l}\text { Maastricht } \\
\text { deficit gap }\end{array}$ \\
\hline Austria & -173 & -514 & 4.0 & 4.5 & 1.2 \\
\hline Belgium & -156 & -427 & 3.7 & 3.9 & 0.8 \\
\hline Bulgaria & 0 & -212 & 0.0 & 1.6 & 0.0 \\
\hline Cyprus & -494 & $-1,793$ & 9.7 & 13.2 & 4.0 \\
\hline Czech Rep. & -256 & -996 & 5.5 & 8.1 & 2.5 \\
\hline Denmark & -2 & 87 & 0.0 & -0.6 & 0.1 \\
\hline Estonia & -200 & -595 & 4.0 & 4.4 & 1.4 \\
\hline Finland & -130 & -552 & 3.0 & 4.9 & 0.5 \\
\hline France & -148 & -339 & 3.4 & 2.9 & 3.1 \\
\hline Germany & -152 & -484 & 3.8 & 4.7 & 0.9 \\
\hline Greece & -418 & $-1,385$ & 11.9 & 15.3 & 5.9 \\
\hline Hungary & 43 & 21 & -1.0 & -0.2 & 0.0 \\
\hline Ireland & -213 & -812 & 5.1 & 7.5 & 5.7 \\
\hline Italy & -110 & -129 & 2.8 & 1.3 & 1.9 \\
\hline Latvia & -20 & -28 & 0.5 & 0.3 & 0.5 \\
\hline Lithuania & -250 & -857 & 6.6 & 8.8 & 6.4 \\
\hline Luxembourg & -383 & $-1,745$ & 8.3 & 14.4 & 1.6 \\
\hline Malta & -188 & -790 & 4.3 & 6.9 & 1.5 \\
\hline Netherlands & -218 & -697 & 5.4 & 6.6 & 1.7 \\
\hline Poland & -72 & -140 & 1.5 & 1.1 & 2.7 \\
\hline Portugal & -106 & -273 & 2.8 & 2.7 & 3.3 \\
\hline Romania & -252 & $-1,097$ & 4.5 & 7.4 & 1.9 \\
\hline Slovak Rep. & -243 & -981 & 4.2 & 6.4 & 0.7 \\
\hline Slovenia & -287 & $-1,262$ & 5.7 & 9.4 & 0.8 \\
\hline Spain & -307 & -986 & 7.9 & 9.8 & 6.2 \\
\hline Sweden & 43 & -25 & -0.9 & 0.2 & 0.0 \\
\hline UK & -172 & -558 & 3.7 & 4.6 & 4.6 \\
\hline EU27 & -153 & -472 & 3.5 & 4.2 & 2.7 \\
\hline
\end{tabular}

Sources: IMFstaff estimates.

\section{Conclusions}

For the EU27 as a whole, the public sector's intertemporal net worth is negative, large, and worsening over time, suggesting an unsustainable long-run position. In contrast to traditional indicators, which capture only the current state of public finances and reflect only a small portion of a government's total obligations, measures of intertemporal net worth also take into account the implications of current policies for future debt. Whether these are computed directly from the EC's Aging Working Group's sustainability indicators, or using the comprehensive balance-sheet approach, for the EU27, they suggest that, while current net worth (net debt) represents only about negative 50 percent of GDP, its intertemporal net worth is deeply negative under the baseline, at around negative 150-500 percent of GDP, depending on the horizon of the measure, and is deteriorating over time. Moreover, the variation among countries is significant, with only a few countries being intertemporally sustainable, due to both early pension reforms that limited their prospective aging costs, and relatively contained debts and deficits entering into the crisis. At the other extreme, a large number of EU members have negative net worth equivalent to several times their GDP level, due to rapidly rising aging costs. Finally, should future health care and pension costs be under-estimated under the baseline, the intertemporal net worth gaps would be even worse. 
The findings imply an urgent need to strengthen fiscal policies in most EU countries to bring future liabilities into line with the governments' capacity to generate assets. As mentioned at the onset of this paper, the intertemporal budget constraint can become binding abruptly, if intertemporal gaps persist and markets become increasingly aware of and unwilling to finance them. Hence, policymakers should proactively reduce such gaps to avoid potentially painful adjustments. The indicators presented here do not provide answers regarding the specific type of policies that would be desirable in each particular country, except to say that they need to be permanent to have an effect on long-run net worth. Hence, they need to be complemented with an analysis of countryspecific circumstances to be able to deliver concrete policy recommendations. However, one observation from this cross-country analysis is that countries that have already reformed their pension systems generally benefit from a stronger long-run position relative to others. Hence, for those countries that have not yet done so, pension reform is of utmost importance. As populations age, so will the median voter, implying that measures needed to address the fiscal costs due to demographic change could become politically more difficult to accept by the public and implement as time goes by. This is another reason why these reforms should not be delayed any further. Finally, broad structural reforms aimed at making labor and product markets more efficient are crucial to increase the level of potential GDP in the long-run, thus helping generate additional revenues and lowering countries' debt burden.

The measures developed in this paper could be used to better gauge relative cross-country fiscal positions. This is particularly important at this juncture, when policymakers, the media, and markets are increasingly scrutinizing public finances. Debt and deficit indicators provide limited information as they are backward looking. Moreover, they are not fully comparable across countries, as only some countries have recognized future pension liabilities explicitly (through pension reform), while many others do not. In contrast, measures of intertemporal net worth such as the ones developed here encompass both backward- and forward-looking elements, making them fully comparable across countries and more reliable as measures of fiscal sustainability (as they are based directly on the intertemporal budget constraint). Markets in particular may pay increasing attention to such measures of the public sector's net worth, which they already employ in the case of individuals and companies.

\section{They could also be helpful in shaping policymaking decisions and strengthening} communication with the public. Given their comprehensiveness and comparability across countries, these measures could usefully complement existing debt and deficit indicators to better inform policymaking decisions at an international level, including in the context of the EU's fiscal mechanisms. Individual countries could publish and update these measures yearly, perhaps in their budget documents, to show how net worth is evolving over time (the thermometer of fiscal health mentioned at the outset of the paper). Policy makers can also use these measures to assess and present planned policy changes to voters. This can illustrate that even relatively modest upfront permanent adjustments can bring large benefits in terms of reducing the negative value of intertemporal net worth over a long period of time. However, it can also show that temporary fixes that lower the deficit but that have no impact on or even worsen long-term liabilities, would correspondingly not affect or worsen the shortfall in intertemporal net worth. 


\section{References}

Auerbach (2008), "Long-Term Objectives for Government Debt," Mimeo, http://www.econ.berkeley.edu/ auerbach/index.html

Auerbach, A., Gokhale, J. and Kotlikoff, L. (1992), "Generational Accounting: a New Approach to Understanding the Effects of Fiscal Policy on Saving," Scandinavian Journal of Economics 94, pp. 303-318.

., Gale, W. and Orszag, P. (2004) "The U.S. Fiscal Gap and Retirement Saving," OECD Economic Studies 39, pp. 9-23.

_., Furman, J. and Gale, W. (2007) Still Crazy After all These Years: Understanding the Budget Outlook," Tax Notes, May 21, pp. 765-778.

Balassone, Fabrizio, Jorge Cunha, Geert Langenus, Bernhard Manzke, Jeanne Pavot, Doris Prammer and Pietro Tommasino (2008), "Fiscal Sustainability and Policy Indicators for the Euro Area," Banque de France, Notes d'Etude et de Recherche, No. 225, http://www.banque-france.fr/gb/publications/telechar/ner/ner225.pdf

Cecchetti, Stephen, M.S. Mohanti, and Fabrizio Zampolli (2010), “The Future of Public Debt: Prospects and Implications," BIS Working Paper No. 300, http://www.bis.org/publ/othp09.pdf

Chand, Sheetal. and Alfred Jaeger (1996), "Ageing Populations and Public Pension Schemes," IMF Occasional Paper, No. 147, http://www.imf.org/external/pubs/cat/longres.cfm?sk=3860.0

Disney, R. (2001), "How Should We Measure Pension Liabilities in EU Countries?," in T. Boeri, A Borsch-Supan, A. Brugiavini, R. Disney, A. Kapteyn and F. Peracchi (eds.), Pension: More Information, Less Ideology, The Netherlands, Kluwer Academic Publisher.

Draxler, Juraj (2009), "How to Make European Pensions Adequate and Sustainable?" CEPS Special Report, March 2009.

European Commission (2008), The 2009 Aging Report: Underlying Assumptions and Projection Methodologies, European Economy 7/2008. - (2009), Sustainability Report 2009, European Economy 9/2009.

Franco, Daniele, Maria Rosaria Marino and Stefania Zotteri (2005), "Pension Expenditure Projections, Pension Liabilities, and European Union Fiscal Rules," Bank of Italy Research Paper, http://www.bancaditalia.it/studiricerche/convegni/atti/fiscal_ind/Fiscal/7.pdf 
Ghezzi, Pierro, and Christian Keller (2010), "Euro Area periphery: Implications of the EU's Mega Package',’ Barclays Capital Economic Research, May 12, 2010.

Gokhale, Jagadeesh (2009), "Measuring the Unfunded Obligations of European Countries," National Center for Policy Analysis, Policy Report No. 319, http://www.cato.org/people/jagadeesh-gokhale

International Monetary Fund (2010), "From Stimulus to Consolidation: Revenue and Expenditure Policies in Advanced and Emerging Economies; IMF Policy Paper; April 30, 2010 , http://www.imf.org/external/np/pp/eng/2010/043010a.pdf

—_, "Navigating the Fiscal Challenges Ahead", IMF Fiscal Monitor, May 14, 2010, http:/www.imf.org/external/pubs/ft/fm/2010/fm1001.pdf

Langenus, Geert (2006), "Fiscal Sustainability Indicators and Policy Design in the Face of Ageing," national Bank of Belgium Working Paper No. 206, http://www.nbb.be/doc/ts/publications/wp/wp102En.pdf

Milesi-Ferretti, Gian Maria and Kenji Moriyama (2004), "Fiscal Adjustment in EU Countries: a Balance Sheet Approach," IMF Working Paper No. 04/143, http://www.imf.org/external/pubs/cat/longres.cfm?sk=17507.0

Traa, Bob (2006), “A Preliminary Public Sector Balance Sheet for Germany,” Germany Selected Issues, http://www.imf.org/external/pubs/cat/longres.cfm?sk=18815.0 (2009), "A Fiscal Early Warning System Based on the Comprehensive Public Sector Balance Sheet," Greece Selected Issues, IMF Country Report No. 09/245, http://www.imf.org/external/pubs/cat/longres.cfm?sk=23170.0

Velculescu, Delia (2010), "A Leap Beyond Traditional Fiscal Indicators: Measuring Poland's Intertemporal Net Worth and Deriving its Policy Implications," Poland Selected Issues, IMF Country Report No. 10/119, http:/www.imf.org/external/pubs/cat/longres.cfm?sk=23861.0

von Hagen, Jurgen and Wolff, Guntram B. (2006), "What do deficits tell us about debt? Empirical evidence on creative accounting with fiscal rules in the EU," Journal of Banking \& Finance, Elsevier, vol. 30(12), pp. 3259-3279, http://ideas.repec.org/p/trf/wpaper/148.html 


\section{Mathematical Appendix: Comprehensive Net Worth and the S1 and S2 Sustainability Indicators}

The intertemporal budget constraint (solvency condition) tests the ability of the government to meet its net debt obligations with a stream of future primary surpluses. For solvency to hold at a given point in time, future primary surpluses have to be equal to or larger than the public sector's debt level $D_{t}$ net of assets $A_{t}$ :

$$
D_{t}-A_{t} \leq \sum_{t=t_{0}}^{\infty} \frac{P B_{t}}{\prod_{n=0}^{t}\left(1+i_{n}\right)}
$$

where $\mathrm{PB}_{\mathrm{t}}$ are the primary balances at each point in time (government receipts minus expenditures net of interest payments), discounted over time by the nominal interest on debt $i_{t}$.

This inequality can be expressed in percent of GDP as:

$$
d_{t}-a_{t} \leq \sum_{t=t_{0}}^{\infty} p b_{t} \prod_{n=0}^{t} \frac{1+g_{t}}{1+i_{t}}=\sum_{t=t_{0}}^{\infty} p b_{t} \cdot \delta_{t}
$$

where $g_{t}$ is the nominal growth rate of GDP, with $\delta_{t}$ being the growth-adjusted time-varying discount factor (the other lower case variables represent ratios to GDP).

If the discounted sum of future primary surpluses exceeds current net debt, the budget constraint is satisfied. If future primary surpluses fall short of net debt, then current fiscal policies would require strengthening to meet the government's solvency condition.

The EC's Aging-Working Group's S2 indicator shows the permanent upfront adjustment to the primary balance required to maintain equality between the current debt level (proxy-ing for current net debt) and the discounted sum of primary balances over an infinite horizon. Mathematically:

$$
d_{t}=\sum_{t=t_{0}}^{\infty} p b_{t} \cdot \delta_{t}=\sum_{t=t_{0}}^{\infty}\left(\overline{p b}_{t}+S 2_{t_{0}}\right) \cdot \delta_{t}=\sum_{t=t_{0}}^{\infty} \overline{p b} \cdot \delta_{t}+S 2_{t_{0}} \sum_{t=t_{0}}^{\infty} \delta_{t}
$$

where $\overline{p b}_{t}$ are primary balances under current policies, $\mathrm{d}_{\mathrm{t}}$ is the level of debt at time $\mathrm{t}$, and $\mathrm{S} 2$ is the amount of adjustment at $t_{0}$.

Hence:

$$
S 2_{t_{0}}=\frac{d_{t}-\sum_{t=t_{0}}^{\infty} \overline{p b}_{t} \cdot \delta_{t}}{\sum_{t=t_{0}}^{\infty} \delta_{t}}
$$

If $\mathrm{S} 2$ is equal or less than zero, then the intertemporal budget constraint is satisfied under current policies. A positive $\mathrm{S} 2$ indicates the size of the upfront fiscal adjustment needed to ensure intertemporal solvency.

The infinite-horizon intertemporal net worth is defined as the total of the discounted sum of future primary balances under current policies and current net worth (which is the difference between assets and liabilities, or the negative of net debt). This can be positive or negative, depending on whether current policies are enough to generate (or not) sufficient primary surpluses in the future to cover current net worth $\left(\mathrm{cnw}_{\mathrm{t}}\right)$. 


$$
\text { inw }_{t}=\sum_{t=t_{0}}^{\infty} \overline{p b}_{t} \cdot \delta_{t}+a_{t}-d_{t}=\sum_{t=t_{0}}^{\infty} \overline{p b}_{t} \cdot \delta_{t}+c n w_{t}
$$

It can be seen then that there exists a direct correspondence between $\mathrm{S} 2$ and intertemporal net worth. Note that in the EC's definition, current net worth equals financial liabilities (not taking into account financial assets), while the definition of intertemporal net worth is broader, taking financial assets, $a_{t}$ into account (though non-financial assets are not included here, for simplicity).

$$
S 2_{t_{0}}=\frac{-i n w_{t}+a_{t_{0}}}{\sum_{t=t_{0}}^{\infty} \delta_{t}} \text { or } i n w_{t}=-S 2_{t_{0}} \cdot \sum_{t=t_{0}}^{\infty} \delta_{t}+a_{t_{0}}
$$

In other words, if the intertemporal net worth is negative, the instantaneous permanent strengthening of the primary balance needed to bring it to zero would be S2. If the INW is positive, the government could afford to run a slightly looser fiscal policy from today onward - S2 would be negative.

As an illustrative example, let's assume that S2 $=4$ percent of GDP, nominal growth is constant at 4 percent and the real interest rate is also constant and equal to 5 percent. Assume assets are zero. The intertemporal (infinite-horizon, financial) net worth is then equal to -420 percent of GDP: ${ }^{21}$

$$
i n w_{t}=-S 2_{t_{0}} \cdot \sum_{t=t_{0}}^{\infty} \prod_{n=0}^{t}\left(\frac{1+0.04}{1+0.05}\right)^{n}=-S 2_{t_{0}} \cdot \sum_{t=t_{0}}^{\infty}\left(\frac{1+0.04}{1+0.05}\right)^{t-t_{0}}=-\frac{S 2_{t_{0}}}{\left(1-\frac{1+0.04}{1+0.05}\right)}=-\frac{4}{\left(\frac{0.01}{1.05}\right)}=-420
$$

Now, if the growth rate is assumed to vary over time, but the interest rate is fixed (as in the EC's 2009 Sustainability Report), it is still possible to obtain the infinite-horizon intertemporal net worth measure directly from the two published subcomponents for S2 for most countries. Recall that S2 is defined as the sum of IBP (the required adjustment given the initial budgetary position) and LTC (the required adjustment to compensate for the long-term change in the primary balance due to population aging). The EC defines IBP as:

$$
I B P=\frac{d_{t}}{\sum_{t=t_{0}}^{\infty} \delta_{t}}-p b_{t-1}-N P V_{t}(\mathrm{P} I)
$$

where $\mathrm{d}$ is gross debt at time $\mathrm{t}$ as a percent of GDP, standing for current net worth and PI is the change in property income, which is assumed to vary over time. However, for most countries (except for Denmark, Lithuania, the Netherlands, Finland and Slovenia), this term is fairly small and, for simplicity, can be ignored. In these cases, it follows that:

$$
\sum_{t=t_{0}}^{\infty} \delta_{t} \approx \frac{d_{t}}{I B P+p b_{t-1}}
$$

${ }^{21}$ The property $\sum_{t=0}^{\infty} x^{t}=\frac{1}{1-x}$ has been used, as $0<\mathrm{x}<1$ is satisfied. 
Hence,

$$
i n w_{t}=-S 2_{t_{0}} \cdot \sum_{t=t_{0}}^{\infty} \delta_{t}+a_{t_{0}} \approx-S 2_{t_{0}} \frac{d_{t}}{I B P+p b_{t-1}}+a_{t_{0}}
$$

Hence, an easy back-of-the envelope calculation of the infinite-horizon intertemporal net worth for the majority of EU countries can be done directly using the published information from the Sustainability Report.

Moreover, this mathematical expression (equation 9) can be quickly updated to include recent estimates of debt and the primary balance (as well as estimates of the government's financial assets). To do so, one should still use the expression obtained in equation (8) for $\Sigma \delta$ and then recalculate S2 as: $S_{2 \text { new }}=I B P_{\text {new }}+L T C=\frac{D_{\text {new }}}{\sum_{t=t_{0}}^{\infty} \delta_{t}}-p b_{\text {new }}+L T C$

The updated infinite-horizon INW would thus be:

$$
i n w_{t}=-S 2_{\text {new }} \cdot \sum_{t=t_{0}}^{\infty} \delta_{t}+a_{t_{0}}
$$

A finite horizon in $w^{*}$ can be defined as the difference between the discounted sum of future primary surpluses under current policies over a specific period of time, and current net

worth. Defining such a measure over a foreseeable period rather than over an infinite period may be easier to grasp by the general public (voters). Moreover, it will help avoid time-consistency problems, and thus strong incentives to postpone painful policies into the (far) future, which plague infinite-horizon budget constraints that, theoretically, could be satisfied by very high levels of shortterm debt and deficits, as long as there is reason to believe that sufficiently large primary surpluses will be achieved afterwards.

The finite horizon inw up to 2060 is therefore defined as:

$$
i n w_{t}^{*}=\sum_{t=t_{0}}^{2060} \overline{p b} \cdot \delta_{t}+c n w_{t}
$$

To see how inw* relates to S2, recall $S 2_{t_{0}}=\frac{c n w_{t}-\sum_{t=t_{0}}^{\infty} \overline{p b} \cdot \delta_{t}}{\sum_{t=t_{0}}^{\infty} \delta_{t}}=\frac{-i n w_{t}^{*}+a_{t_{0}}-\sum_{t=2060}^{\infty} \overline{p b} \cdot \delta_{t}}{\sum_{t=t_{0}}^{\infty} \delta_{t}}$

Hence: $\quad i n w_{t}^{*}=-S 2_{t_{0}} \cdot \sum_{t=t_{0}}^{\infty} \delta_{t}-\sum_{t=2060}^{\infty} \overline{p b} \cdot \delta_{t}+a_{t_{0}}$

From this expression it can be seen that the finite horizon inw* will be less than its infinite horizon counterpart by an amount that depends on the long-run primary fiscal balance. 
If it can be assumed that from 2060 onward, the real interest rate, GDP growth rate, and the primary balance are constant, and $\mathrm{i}>\mathrm{g}$, then inw* becomes: ${ }^{22}$

$i n w_{t}^{*}=-S 2_{t_{0}} \cdot\left(\sum_{t=t_{0}}^{2060} \delta_{t}+\sum_{t=2060}^{\infty} \delta_{t}\right)-\overline{p b}_{2060} \sum_{t=2060}^{\infty} \delta_{t}+a_{t_{0}}=-S 2_{t_{0}} \cdot \sum_{t=t_{0}}^{2060} \delta_{t}-\left(S 2_{t_{0}}+\overline{p b}_{2060}\right) \cdot \delta_{2060} \cdot \sum_{t=2060}^{\infty}\left(\frac{1+g}{1+r}\right)^{t-t_{0}}+a_{t_{0}}$

Or

$$
i n w_{t}^{*} \approx-S 2_{t_{0}} \cdot \sum_{t=t_{0}}^{2060} \delta_{t}-\left(S 2_{t_{0}}+\overline{p b}_{2060}\right) \frac{\delta_{2060}}{1-\frac{1+g}{1+r}}+a_{t_{0}}
$$

Taking the same example as before (S2=4 percent of GDP, growth is constant throughout the period at 4 percent and the interest rate is also constant and equal to 5 percent) and also assuming that the primary balance is -4 percent of GDP from 2060 onwards and assets are zero, then the finite horizon intertemporal net worth is approx. -160 percent of GDP:

$$
i n w_{t}^{*}=-4 \cdot \frac{1}{1-\frac{1.04}{1.05}}-(-4) \frac{\left(\frac{1.04}{1.05}\right)^{50}}{1-\frac{1.04}{1.05}}=-420 *\left[1-\left(\frac{1.04}{1.05}\right)^{50}\right]=-160
$$

This example shows that indeed the finite horizon inw is smaller than its infinite horizon counterpart when primary balances continue to remain negative (due to aging, for instance) over the long run. Still, in this example, this measure conveys the message that, even if one were to ignore very long-run fiscal costs (which are still sizeable at 4 percent of GDP), current policies are still insufficient to cover the current gap between the government's assets and liabilities, requiring an additional effort from the authorities to make net worth non-negative over the foreseeable future.

The S1 indicator is also finite-horizon measure showing the permanent upfront adjustment to the structural primary balance required to reach a target gross debt level of 60 percent of GDP in 2060. The choice of the debt target for the $S 1$ indicator is in line with the debt threshold in the Maastricht Treaty. The timescale has been chosen to be long enough to allow the impact of ageing to be analyzed in a meaningful way, while still remaining within the sight of current taxpayers and policy makers. The condition for the S1 indicator can be expressed as:

$$
\text { Debt }_{t}-60 \cdot \delta_{2060}-\sum_{t=t_{0}}^{2060-t_{0}}\left(\overline{p b}_{t}+S 1_{t_{0}}\right) \cdot \delta_{t}=0 \text {, hence: } S 1_{t_{0}}=\frac{D e b t_{t}-60 \cdot \delta_{2060}-\sum_{t=t_{0}}^{2060-t_{0}} \overline{p b} \cdot \delta_{t}}{\sum_{t=t_{0}}^{2060-t_{0}} \delta_{t}}
$$

A negative $\mathrm{S} 1$ indicator implies that current policies are sufficient to ensure that debt will reach 60 percent of GDP by 2060, while a positive value of S1 indicates the size of the upfront fiscal adjustment needed to ensure that debt satisfies the Maastricht limit by 2060.

${ }^{22}$ Here we approximate sums with integrals: $\sum_{t=a}^{b} x^{t}=\int_{a}^{b} x^{t} d t=\frac{x^{b}-x^{a}}{\ln x}$ and also use $\frac{-1}{\ln x}=\frac{1}{1-x}$ 
The finite-horizon inw can also be derived directly from S1. We can use the same definition as before for inw* over the period up to 2060: $i n w_{t}^{*}=\sum_{t=t_{0}}^{t_{0}-2060} \overline{p b} \cdot \delta_{t}+c n w_{t}$

From the expression for $\mathrm{S} 1$, we can obtain the relationship between it and inw ${ }^{*}$ :

$$
S 1_{t_{0}}=\frac{-i n w_{t}^{*}-60 \cdot \delta_{2060}+a_{t}}{\sum_{t=t_{0}}^{2060-t_{0}} \delta_{t}} \text { or } i n w_{t}^{*}=-S 1_{t_{0}} \cdot \sum_{t=t_{0}}^{2060-t_{0}} \delta_{t}-60 \cdot \delta_{2060}+a_{t}
$$

As an example, let's assume that S1 $=3$ percent of GDP, growth is constant at 4 percent and the interest rate is also constant and equal to 5 percent. Let's assume that there are no financial assets. Then, the intertemporal (finite-horizon, financial) net worth is then equal to approximately -157 percent of GDP, of which 120 percent of GDP is the difference between the discounted sum of primary balances and the gap between the current net worth and the Maastricht limit in 2060, and 37 percent of GDP is the additional gap from the Maastricht limit to zero, discounted back to the present.

$$
i n w_{t}^{*} \approx-3 \cdot \frac{1-\left(\frac{1.04}{1.05}\right)^{50}}{\frac{0.01}{1.05}}-60 \cdot\left(\frac{1.04}{1.05}\right)^{50}=-120-37=-157
$$

Similar to the infinite-horizon case, if the growth rate is assumed to vary over time, but the interest rate is fixed (as in the EC's 2009 Sustainability Report), it is still possible to obtain the infinitehorizon intertemporal net worth measure directly from the three published subcomponents for S1 for most countries. Recall that S2 is defined as the sum of IBP (the required adjustment given the initial budgetary position), DR (the adjustment needed to reach a debt of 60 percent of GDP by 2060), and LTC (the required adjustment to compensate for the long-term change in the primary balance due to population aging). The EC defines IBP and DR as:

$$
I B P=\frac{D_{t}\left(\frac{1}{\delta_{60}}-1\right)}{\frac{\sum_{t=t_{0}}^{2060} \delta_{t}}{\delta_{60}}-1}-p b_{t-1}-N P V_{t}(\mathrm{P} I) \quad D R=\frac{D_{t}-60}{\frac{\sum_{t=t_{0}}^{2060} \delta_{t}}{\delta_{60}}-1}
$$

where $\mathrm{D}$ is gross debt at time $\mathrm{t}$, and PI is the change in property income, which is assumed to vary over time. However, for most countries (except for Denmark, Lithuania, the Netherlands, Finland and Slovenia), this term is fairly small and, for simplicity, can be ignored. In these cases, it follows that:

$$
\begin{gathered}
\delta_{60}=\frac{D R \cdot D_{t}}{D R \cdot D_{t}+\left(1+I B P+p b_{t-1}\right)\left(D_{t}-60\right)} \\
\sum_{t=t_{0}}^{2060} \delta t=\frac{D_{t} \cdot\left(D_{t}-60+D R\right)}{D R \cdot D_{t}+\left(1+I B P+p b_{t-1}\right)\left(D_{t}-60\right)}
\end{gathered}
$$


Recall that: $\operatorname{inw}_{t}^{*}=-S 1_{t_{0}} \cdot \sum_{t=t_{0}}^{2060-t_{0}} \delta_{t}-60 \cdot \delta_{2060}+a_{t}$

Hence:

$$
\operatorname{inw}^{*} \approx \frac{d_{2010}}{D R \cdot d_{2010}+\left(I B P_{S 1}+p b_{2009}\right)\left(d_{2010}-60\right)}\left[\left(d_{2010}-60+D R\right) S 1-60 \cdot D R\right]+a_{2010}
$$

Now, to update this estimate with recent data for debt and the primary balance, one should use the expressions for $\delta$ and $\Sigma \delta$ obtained in equations 19 and 20 and calculate updated values for DR and IBP:

$$
I B P_{\text {new }}=\frac{D_{\text {new }}\left(\frac{1}{\delta_{60}}-1\right)}{\frac{\sum_{t=t_{0}}^{2060} \delta_{t}}{\delta_{60}}-1}-p b_{\text {new }}
$$

$$
D R_{\text {new }}=\frac{D_{\text {new }}-60}{\frac{\sum_{t=t_{0}}^{2060} \delta_{t}}{\delta_{60}}-1}
$$

in order to obtain a new updated value for S1, which can be used to derive inw*:

$$
\begin{gathered}
S_{1 \text { new }}=I P B_{\text {new }}+D R_{\text {new }}+L T C \\
i n w_{\text {new }}^{*}=-S 1_{\text {new }} \cdot \sum_{t=t_{0}}^{2060-t_{0}} \delta_{t}-60 \cdot \delta_{2060}+a_{t}
\end{gathered}
$$

